Optimal Health and Environmental Policies in a Pollution-Growth Nexus

Min Wang, Jinhua Zhao, Joydeep Bhattacharya

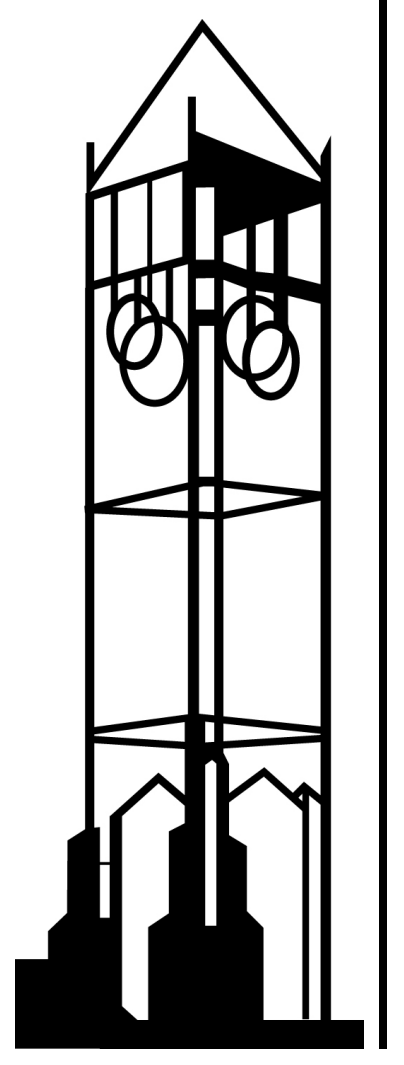

Working Paper No. 13006

March 2013

IOWA STATE UNIVERSITY

Department of Economics

Ames, lowa, 50011-1070

lowa State University does not discriminate on the basis of race, color, age, religion, national origin, sexual orientation, gender identity, genetic information, sex, marital status, disability, or status as a U.S. veteran. Inquiries can be directed to the Director of Equal Opportunity and Compliance, 3280 Beardshear Hall, (515) 294-7612. 


\title{
Optimal Health and Environmental Policies in a Pollution-Growth Nexus
}

\author{
Min Wang* \\ Peking University
}

Jinhua Zhao ${ }^{\dagger}$

Michigan State University

Joydeep Bhattacharya ${ }^{\ddagger}$

Iowa State University

March 8, $2013^{\S}$

\begin{abstract}
This paper shows how policies aimed at insuring health risks and those intended to improve the environment are (and should be) deeply intertwined. In the model economy, inspired by recent Chinese experience, pollution raises the likelihood of poor health in the future prompting agents to self insure against anticipated, rising medical expenses. The increased saving generates more capital while capital use by firms generates more pollution. Along the transition, such a pollution-growth nexus may be attractive from a capital-accumulation perspective; however, rising pollution, via the health channel, definitely hurts welfare. Availability of private health insurance to top up pay-as-you-go coverage of medical bills together with a Pigouvian tax on emissions can replicate the first best.
\end{abstract}

\footnotetext{
${ }^{*}$ National School of Development, Peking University, P.R. China. E-mail: wangmin@nsd.edu.cn

${ }^{\dagger}$ Department of Economics, Department of Ag., Food and Res., Economics, and Environmental Science and Policy Program, Michigan State University, East Lansing, MI 48824, USA. E-mail: jzhao@msu.edu.

${ }^{\ddagger}$ Department of Economics, Iowa State University, Ames IA 50011-1070, USA. E-mail: joydeep@iastate.edu

$\S$ We thank participants at the 9th Annual Missouri Economics Conference, the 2009 Agricultural and Applied Economics Association Annual Meetings in Milwaukee, and the Economic Theory Seminar at Michigan State University for their helpful comments. We also thank two anonymous referees and a coeditor for their detailed and extremely helpful comments. The standard disclaimer applies.
} 


\section{Introduction}

That a country's environment - the air its people breathe, the water they drink, and so on - will have a profound effect on its overall economic performance hardly seems surprising. In fact, it is almost commonplace to think that poor air or low water quality will negatively impact the lives of people and prevent them from being at their productive best. And yet, even as the world economy slowly adjusts to a changing economic order with the BRIC (Brazil, Russia, India and China) countries developing at stupendous rates, images of people on the streets of Mumbai or Rio or Beijing going about their business wearing face masks are hard to suppress. ${ }^{1}$ Are these countries choking on their success? Is such progress desirable? What about the health consequences, and associated health costs of such rampant pollution? How does availability and design of health insurance systems play into this trade-off? This paper is an attempt to present a framework to answer such questions.

These questions are not merely of academic interest; they affect the lives of millions and have deep policy consequences. The New York Times (2007) report on environmental degradation in China describes the situation in China in fairly graphic terms: “... just as the speed and scale of China's rise as an economic power have no clear parallel in history, so its pollution problem has shattered all precedents. [...] Public health is reeling. Pollution has made cancer China's leading cause of death, the Ministry of Health says. Ambient air pollution alone is blamed for hundreds of thousands of deaths each year." For several days in January 2013, Beijing's air quality index went "off the charts" with readings above 700 on certain days (New York Times, 2013). Partly in response to the public health crisis precipitated by rapid environmental degradation, China announced in 2009 an ambitious plan to provide universal health care by 2020. A 2011 New York Times report documents that with increased public spending totaling $\$ 27$ billion during 2009-2011 on insurance premium subsidies and health care infrastructures, China now provides about $95 \%$ (up from a mere $30 \%$ in 2003) of its people some kind of basic insurance coverage. A major consequence of such coverage expansion is that out-of-pocket spending as percentage of China's total health expenditure went down from $55.8 \%$ in 2003 to $35.5 \%$ in 2010 . What is the likely impact of such health insurance on the Chinese economy? Will there be environmental consequences of such health policy? Are health and environment-improvement policies inextricably intertwined?

\footnotetext{
${ }^{1}$ As the New York Times (2007) report puts it, "Environmental woes that might be considered catastrophic in some countries can seem commonplace in China: industrial cities where people rarely see the sun; children killed or sickened by lead poisoning or other types of local pollution; a coastline so swamped by algal red tides that large sections of the ocean no longer sustain marine life."
} 
Our model is designed to answer the aforementioned questions, and works off two main linkages each with important empirical backing. First is the link between pollution and ill health. In recent years, epidemiological research has discovered consistent evidence of the damaging effects of pollution on human health - see Brunekreef and Holgate (2002) for a good survey of this literature. ${ }^{2}$ A variety of cohort studies (e.g., Dockery (1993) and Pope et al. (1995, 2002)) and daily time series studies (see, e.g., Samet et. al. (2000), Daniels et. al. (2000)), respectively, have documented the long and short-term effects of air pollution on respiratory and cardiovascular illness and the associated morbidity and mortality effects. ${ }^{3}$ Using U.S. national survey data, Evans and Smith (2005) also confirm that current and long-term exposure to air pollution (particulate matter and ozone) significantly increases the risk of heart attacks, angina, chronic lung disease and shortness of breath for the elderly. ${ }^{4}$ In our model, we incorporate the essence of such damning evidence by assuming that pollution raises the likelihood of poor health for the elderly. ${ }^{5}$ The second main link we utilize is the one connecting increased risk of future ill health to higher (precautionary) saving. Chamon and Prasad (2010) use household survey data to explore the high and rising savings rates in urban China. Their regression results suggest that health risk-induced precautionary savings could explain a large fraction of overall household savings - it has almost a 20 percentage point effect on the savings rate. ${ }^{6}$

\footnotetext{
${ }^{2}$ A snapshot of the findings of Brunekreef and Holgate (2002) is highly suggestive of the extent of the damage to health caused by pollution : "For Austria, France, and Switzerland combined (population about 74.5 million), 40,000 deaths per year are estimated to be attributable to air pollution, about half to air pollution from traffic specifically. Similarly high numbers have been estimated for respiratory and cardiovascular hospital admissions, bronchitis episodes, and restricted activity days. Because of such numbers, health effects from air pollution have been estimated to be higher than effects from a long list of other environmental factors."

${ }^{3}$ Water pollution is another major source of health problems, especially in poor areas that cannot access piped water. WHO (2006) has reported on the negative health impact of a wide variety of chemical and microbial pollutants in drinking water.

${ }^{4}$ Kan et. al (2008) conduct a time-series analysis to examine the modifying effect of season, sex, age, and education on the association between outdoor air pollutants (PM10, sulfur dioxide, nitrogen dioxide, and ozone) and daily mortality in Shanghai, China, using 4 years of daily data collected between 2001-2004. They find that among those older than 65 years of age, the effect estimates of all four pollutants were significant, and approximately two to five times higher than among all younger people.

${ }^{5}$ The negative effect on health is certainly not the only damage that pollution generates. But it is undoubtedly the costliest, as inferred from contingent-valuation studies of willingness-to-pay for pollution reduction. For example, in 2003 the estimated mean monetary health costs of air and water pollution in China were estimated to be 520 billion yuan (3.8 percent of GDP) and 66 billion yuan respectively. In contrast, the non-health damage which includes crop loss, fishery loss and material erosion etc., was estimated to be about 50 billion yuan (World Bank and World Bank and State Environmental Protection Administration of P.R. China, 2007).

Similar evidence exists for developed countries. The U.S. EPA (1997) estimates that during 1970-1990, the mean value of total monetized human health benefits of the Clean Air Act was $\$ 22$ trillion. In contrast, the non-health gains in household cleanliness, agriculture and visibility value were $\$ 74$ billion, $\$ 11$ billion, and $\$ 38$ billion respectively.

${ }^{6}$ Palumbo (1999) uses Panel Study of Income Dynamics data to estimate consumption for American retirees. He finds that a lifecycle model with uncertain health status predicts their consumption better than a model with uncertain longevity and concludes that uncertain out-of-pocket medical expenses represent an important motive for
} 
We present a fairly standard life-cycle model inspired in part by recent Chinese experiences. The model incorporates health risk and the above-mentioned two linkages; specifically, we extend Kotlikoff (1989) to allow for pollution to be a by-product of economic activities (as in Gradus and Smulders, 1993) and be the dominant determinant of future health risk. In our model, young agents are perfectly healthy. Health status when old, however, can either be poor or good (same as youngage health) and the likelihood of realizing a poor health shock depends on the stock of ambient pollution. An elderly agent with poor health status recovers his health fully by incurring out-ofpocket, curative medical expenses that are tied to pollution levels. Anticipating this possibility, a young agent makes both life-cycle and precautionary savings. Higher pollution levels, by raising the risk of ill health when old and higher medical expenses, provide impetus for more saving. ${ }^{7}$ Ceteris paribus, for a closed economy, more saving increases capital formation leading to more capital use by firms and more pollution, thereby generating a pollution-growth nexus. ${ }^{8}$

In the market economy, pollution and capital reinforce each other along the transition path. Such a path may look attractive from the standpoint of capital accumulation but, as we show, the accompanying pollution significantly hurts welfare. Because of the public-good nature of pollution, the market equilibrium is not efficient. There are two main inefficiencies: no possibility for consumption smoothing or health-risk sharing for the elderly, and the absence of mechanisms to internalize the pollution externality of capital. A benevolent social planner would achieve perfect risk sharing and devote real resources to pollution abatement.

Inspired by the Chinese experience, we study policy interventions that, directly or indirectly, try to nudge the economy closer to the socially optimal outcome. We start by evaluating two health insurance schemes, fully-private health insurance and pay-as-you-go (PAYG) publicly-funded health insurance akin to the U.S. Medicare system. In the former, forward-looking young agents, anticipating future out-of-pocket medical spending, pay premiums to a zero-profit insurance company and buy (partial) coverage against such expenses. In the latter, young agents pay a lump-sum tax, the proceeds from which are used to cover the medical bills of the ill old in the same period. As in Kotlikoff (1989), we find that availability of private insurance does achieve full risk sharing and may

precautionary savings among the elderly; specifically, medical expenses-induced precautionary savings could account for $7 \%$ of annual consumption during the early years of retirement.

${ }^{7}$ Soretz (2003) studies a "reverse" mechanism in which a higher production uncertainty might lead to more pollution. As uncertainty rises, an agent with a sufficiently high relative risk aversion coefficient increases his precautionary savings, which then crowds out pollution abatement expenditure, thereby raising net pollution.

${ }^{8}$ We repeatedly use the term "pollution-growth nexus" as a popular stand-in for the more technically correct but somewhat awkward "pollution-capital accumulation nexus". In the model economy, there is no long-run growth, only capital accumulation and growth in the transition to the steady state. 
reduce the long-run capital stock (relative to the market outcome in the absence of any insurance scheme). Since capital use is the only source of pollution, the latter effect helps reduce long-run pollution. In contrast, an optimally chosen PAYG scheme does not achieve full risk sharing but is able to reduce pollution levels below what is possible under private insurance. We go on to evaluate the effects of a Pigouvian tax on emissions. Such a pollution tax reduces pollution, but introduces a needless distortion in the rate of return to capital. Finally, we show that a set of multiple instruments, including the availability of private health insurance to top up PAYG coverage of medical bills along with a Pigouvian tax on emissions, can replicate the first best. It is in this precise sense that health and environment-improvement policies are (and ought to be) interconnected.

The growth-and-environment literature has largely ignored the issue of health and its connection to the mutually-reinforcing pollution-growth nexus. In part, this is because the existing work focuses on the amenity and productive value of the environment and asks how a more ambitious environmental policy affects long-run growth. In such work, because agents are assumed to have preferences over environmental quality, environmental policy or pollution abatement is a necessity for optimality. ${ }^{9}$ Moreover, since pollution abatement always requires a capital input, environmental policy necessarily crowds out capital investment, thereby constraining long-run growth. On the flip side, pollution abatement could lead to an increase in human capital (Gradus and Smulders, 1993) and/or factor productivity (Bovenberg and Smulders, 1995, 1996), and through these channels, enhance long-run growth. It all boils down to which effect of environmental policy is dominant. Other studies, such as John et. al (1995), Ono (1996) and Stokey (1998), focus on planning solutions for an economy with pollution and study ways to decentralize them via suitable governmental policies. ${ }^{10}$ Often, a critical assumption - additively-separable disutility of pollution - is made thereby precluding any direct effect of pollution on the resource allocation problem of the agent. A major novelty of our paper is this oft-ignored dimension.

Our paper belongs to a short line of papers investigating the nexus between pollution, health, and economic activity. ${ }^{11}$ Recent studies, such as Pautrel (2008), Gutierrez (2008), Mariani et

\footnotetext{
${ }^{9}$ The literature on environment and growth dates back to Gruver (1976) which studies how pollution affects intertemporal resource allocation and why optimal capital accumulation should be less than that under the traditional golden rule.

${ }^{10}$ Utilizing the overlapping generations framework, John and Pecchenino (1994) stress the intergenerational conflict of interest. In their study, a one-period lived government collects taxes from the young and use the proceeds to improve old-age environmental quality. They show how different correlations between environmental quality and income are possible, as is the possibility of multiple steady states and overmaintenance of the environment.

${ }^{11}$ William $(2002,2003)$ introduces health in a static model to re-examine the "double dividend" hypothesis of environmental taxes, where pollution increases sickness time and medical expenses. Here a Pigouvian tax typically reduces welfare because the health effects of pollution aggravate existing distortions in the labor market. In contrast,
} 
al. (2010) and Jouvet et al. (2010), have begun to explore the dynamic effects of pollution on health. Pautrel (2008) shows that when pollution affects the probability of death, more pollution increases the frequency of replacement of generations, reducing the accumulation of aggregate human capital and the long-run optimal growth rate. Mariani et al. (2010) presents a overlappinggenerations $(\mathrm{OG})$ model where life expectancy and environment quality are jointly determined, and shows that longevity is positively correlated with environment quality. The correlation leads to multiple equilibria: low (high) life-expectancy with low (high) environmental-quality. Jouvet et al. (2010) study the design of optimal policies in a two-period OG model in which longevity is positively influenced by health expenditure but negatively influenced by pollution. Goenka, Jafarey, and Pouliot (2012) and Palivos and Varvarigos (2011) also study various issues relating to multiple steady states, poverty traps and cycles in a OG model where mortality risk is connected to environmental quality. We differ from these studies mainly in two aspects. First, while these papers focus on the effect of pollution on mortality, our paper puts the spotlight on morbidity. This focus on morbidity is not simply an innocuous modeling variation; instead, it is motivated by the observation that while many low-pollution countries have low life expectancy, some high-pollution countries, such as China, also have high life expectancy. Second, the morbidity-pollution linkage allows us to explore a novel inter-connection between health insurance systems and environmental policies.

A paper that is close in spirit to ours is Gutierrez (2008). She studies a model similar to ours in which old agents must incur medical expenses that are formulaically tied to the existing stock of pollution. Hers too is a dynamic, general equilibrium OG model in which pollution is a stock that accumulates over time. She finds that more pollution is associated with more capital and higher future pollution. This is because pollution raises old-age health costs requiring agents to increase saving. In this respect, our pollution-growth-nexus result is very similar. Where we differ from Gutierrez (2008) is in the focus and one crucial detail. In our setup, environmental degradation raises the likelihood of poor old-age health; for her, the effect is certain. This one change allows us to focus on how pollution-induced health risk affects individual saving, and as such, how interactions between health insurance systems and environmental policies affect pollution. Such matters cannot be (are not) her concern; instead, her emphasis is on whether the presence of pollution makes it more probable that the market outcome will be dynamically inefficient. In her setup, if the

our paper shows that in dynamic settings, a Pigouvian tax by correcting the intertemporal distortion due to pollutioninduced over-accumulation of capital may generate a double dividend. 
economy with pollution over-accumulates capital (relative to an appropriately-defined golden rule), there are ways to tax production (the source of pollution) or impose labor/capital taxes so as to restore dynamic efficiency. For us, the same gets more nuanced as health insurance systems and environmental policies have to get inextricably entwined to achieve social optima.

The rest of the paper is organized as follows. Section 2 sets up the model and Section 3 analyzes the effects of pollution on capital accumulation in an overlapping generations economy without health insurance or government intervention. We then solve the social planner's problem in section 4. In Sections 5 and 6, we compare different health insurance systems and environmental policies, and design the optimal policy scheme. We conclude in Section 7. Proofs of major results are in the Appendix.

\section{The model}

\subsection{Preferences and technology}

We study an economy consisting of an infinite sequence of two period-lived overlapping generations, an initial-old generation, and an infinitely-lived government. Let $t=0,1,2, \ldots$ index time. At each date $t$, a new generation is born, comprised of a continuum of identical members assumed to be of measure one. Each agent is endowed with one unit of labor when young and retires when old.

There is a single final good produced with a constant returns to scale production function $F\left(K_{t}, L_{t}\right)$ where $K_{t}$ denotes the capital input and $L_{t}$ denotes the labor input at $t$. Defining $k_{t} \equiv$ $K_{t} / L_{t}$, output per young agent at time $t$ can be expressed as $f\left(k_{t}\right)$, where $f\left(k_{t}\right) \equiv F\left(k_{t}, 1\right)$ is the intensive production function. We assume that $f$ takes the Cobb-Douglas form, i.e.,

$$
f\left(k_{t}\right)=A k_{t}^{\alpha}, A>0, \alpha \in(0,1) .
$$

Since the measure of the members of each generation is one, we know $L_{t}=1$ and thus $k_{t}=K_{t}$. The final good can either be consumed in the period it is produced, or it can be saved to provide capital in the following period. Capital is conveniently assumed to depreciate $100 \%$ between periods. Young agents supply labor inelastically in competitive labor markets, earning a wage of $w_{t}$ at time $t$; similarly, capital is traded in competitive capital markets, and earns a gross real return of $R_{t+1}$ between $t$ and $t+1$.

All young agents are assumed healthy. However, the health status of the old can either be "good" or "poor"; specifically, an agent born at date $t$ finds himself in poor health at the start of 
$t+1$ with probability $\sigma_{t+1}$. Let $\delta$ be the subjective discount factor, $c_{t}^{y}$ be the consumption of a young agent at date $t, c_{t+1}^{o, d}$ be the consumption of an old agent in poor health at $t+1$, and $c_{t+1}^{o}$ be the consumption of an old agent in good health at date $t+1$. Inspired by Kotlikoff (1989), the expected life time utility of an agent born at date $t$ is assumed to be

$$
U_{t} \equiv \frac{\left(c_{t}^{y}\right)^{1-\epsilon}}{1-\epsilon}+\delta \frac{\sigma_{t+1}\left(c_{t+1}^{o, d}\right)^{1-\epsilon}+\left(1-\sigma_{t+1}\right)\left(c_{t+1}^{o}\right)^{1-\epsilon}}{1-\epsilon}, \quad t=1,2, \ldots
$$

where $\epsilon>0$ is the intertemporal elasticity of substitution. ${ }^{12}$ We assume that the probability of poor health $\sigma_{t+1}$ depends on the current period aggregate level of pollution $P_{t+1}$ :

$$
\sigma_{t+1}=\sigma\left(P_{t+1}\right)
$$

and $\sigma(\cdot)$ is a non-decreasing, concave function satisfying $\sigma(\cdot) \in[0,1] .{ }^{13}$ Parameter $\sigma(0) \geq 0$ is an exogenous summary measure of the basic health level of the economy. ${ }^{14}$ Private agents take $\sigma_{t+1}$ as parametric when solving their own problems.

As is fairly standard, pollution is modeled as an "inevitable side-product" of production-related activity by firms. For analytical tractability, it is assumed that pollution is a by-product of capital use itself. In particular, the stock of pollution at the start of $t+1$ is a proportion of the past pollutant stock, plus flow emissions that are proportional to capital use during period $t$, net of any direct pollution-abatement activity incurred during period $t$ :

$$
P_{t+1}=(1-\zeta) P_{t}+\rho k_{t}-G\left(q_{t}\right)
$$

Here $\zeta$ is the natural absorption coefficient, $q_{t}$ is the total expenditure on pollution abatement and $G(\cdot)$ describes the abatement technology. We assume $G\left(q_{t}\right)$ is non-decreasing and concave in $q_{t}$ with $G(0)=0$ and $\lim _{q_{t} \rightarrow 0} G^{\prime}\left(q_{t}\right)=\infty$. The coefficient $\rho$ denotes the amount of pollution generated by the use of an additional unit of capital (recall that $k_{t}=K_{t}$ ). We posit that nations differ in this pollution intensity presumably due to unmodelled heterogeneity in endowments, technologies, and industrial structures. We will study long-run developmental and health implications of such

\footnotetext{
${ }^{12}$ Several points about this specification deserve mention. First, unlike in Gradus and Smulders (1993) and others, pollution does not enter the utility function directly. Secondly, health status per se does not enter the utility function as it does in Palumbo (1999) or Pautrel (2012). All agents care about is the potential for income loss arising from the need to incur curative medical expenditures. There is no utility loss associated with the bad health outcome as in Kotlikoff (1989).

${ }^{13}$ As shown in (4), $P_{t+1}$ is the pollution level at the beginning of period $t+1$, which depends on emissions occurred in period $t$. As such, function $\sigma(\cdot)$ captures the health effects of long-term exposures to pollution, i.e., of exposure to pollution when the agent is young.

${ }^{14}$ Presumably, poorer countries with small, inefficient public health systems have higher $\sigma(0)$ than richer countries.
} 
differences. As will become clear, pollution is a public bad - it raises the chance of old-age ill health for all agents. It can be mitigated indirectly by reducing capital use or by direct, costly abatement. Given the public good nature of pollution, neither consumers nor producers (there are infinite numbers of both) have any incentive to pay for the direct abatement activity; hence $q_{t}=0$ must hold in a market economy, and in that case, $P_{t+1}=(1-\zeta) P_{t}+\rho k_{t}$.

We emphasize that any health damage from pollution is restricted to heightened morbidity and has no effect on mortality. An agent who realizes a poor health status recovers her health fully by incurring medical expenses of $m_{t+1}$ where $m_{t+1} \equiv m\left(P_{t+1}\right)$ with $m^{\prime}\left(P_{t+1}\right) \geq 0$. This is in line with Gutierrez (2008) who assumes the older generation incurs health costs which depend on the current pollution stock.

\subsection{Agent's problem}

The agent faces the following per-period budget constraints:

$$
\begin{aligned}
& s_{t}+c_{t}^{y}=w_{t} \\
& c_{t+1}^{o, d}+m\left(P_{t+1}\right)=s_{t} R_{t+1} \\
& c_{t+1}^{o}=s_{t} R_{t+1} .
\end{aligned}
$$

along with $c_{t}^{y} \geq 0, c_{t+1}^{o, d} \geq 0$, and $c_{t+1}^{o} \geq 0$. In (5), the agent when young allocates his labor income between consumption and saving. Saving $s_{t}$ returns $s_{t} R_{t+1}$ in the next period. Equation (6) is the budget constraint for the old in poor health: he allocates his income between consumption and medical expenses. Equation (7) is the budget constraint for the old in good health.

With perfect foresight regarding $R_{t+1}$, and taking $w_{t}$ and $\sigma_{t+1}$ as given, a young agent at date

$t$ chooses $c_{t}^{y}, s_{t}, c_{t+1}^{o, d}$ and $c_{t+1}^{o}$ to maximize the expected lifetime utility (2), subject to (5)-(7). The optimal saving $s_{t}$ is implicitly given by

$$
\delta \sigma_{t+1} R_{t+1}\left[s_{t} R_{t+1}-m\left(P_{t+1}\right)\right]^{-\epsilon}+\delta\left(1-\sigma_{t+1}\right) R_{t+1}\left(s_{t} R_{t+1}\right)^{-\epsilon}-\left(w_{t}-s_{t}\right)^{-\epsilon}=0 .
$$

Proposition $1 \frac{\partial s_{t}}{\partial \sigma_{t+1}}>0$ and $\frac{\partial s_{t}}{\partial P_{t+1}}>0$ : private saving is increasing in the health risk as well as the level of pollution.

Pollution raises individual savings through the precautionary savings channel, and does so in two ways. The first is via the health risk: if the risk of poor health $\sigma_{t+1}$ rises, future consumption becomes more risky, and agents save more in an attempt to smooth the risk. The second is via 
expenditure on health restoration: anticipation of increased health expenditures induces agents to save more so as to smoothen consumption.

Two points deserve mention here. First, our utility formulation makes optimal saving dependent on the interest rate. Second, although a closed-form solution for individual saving is not feasible, saving is bounded between two levels, $s_{t}^{\min }$ and $s_{t}^{\max }$ corresponding to $\sigma_{t+1}=0$ and 1 . When $\sigma_{t+1}=0$, the level of savings, $s_{t}^{\min }=w_{t} /\left(1+\delta^{-1 / \epsilon} R_{t+1}^{1-1 / \epsilon}\right)$, corresponds to the usual lifecycle savings. Pollution or health risk-induced precautionary saving is then given by $\left(s_{t}-s_{t}^{\min }\right)$. In passing, note that the current setup collapses to the certainty-saving model of Gutierrez (2008) when $\sigma_{t+1}=1$. In that case, the old have poor health for sure and saving is given by $s_{t}^{\max }=$ $\left[w_{t}+\left(\delta R_{t+1}\right)^{-1 / \epsilon} m\left(P_{t+1}\right)\right] /\left(1+\delta^{-1 / \epsilon} R_{t+1}^{1-1 / \epsilon}\right)$.

\section{Market equilibrium}

Young agents supply labor inelastically in competitive labor markets, earning a wage of $w_{t}$ at time $t$, where

$$
w_{t} \equiv w\left(k_{t}\right)=f\left(k_{t}\right)-k_{t} f^{\prime}\left(k_{t}\right)
$$

Capital is traded in competitive capital markets, and earns a gross real return of $R_{t+1}$ between $t$ and $t+1$, where

$$
R_{t+1} \equiv R\left(k_{t+1}\right)=f^{\prime}\left(k_{t+1}\right)
$$

with $R^{\prime}\left(k_{t+1}\right)<0$. Since $f(k)=A k^{\alpha}$, we know $w(k)=(1-\alpha) A k^{\alpha}$ and $R(k)=\alpha A k^{\alpha-1}$.

Substituting equilibrium prices and the general-equilibrium condition $s_{t}=k_{t+1}$ into (8) and (4), and using (9) and the fact that $q_{t}=0$ without government intervention, we obtain a twodimensional, first-order dynamical system of the economy:

$$
\begin{aligned}
& \delta \sigma\left(P_{t+1}\right) R\left(k_{t+1}\right)\left[R\left(k_{t+1}\right) k_{t+1}-m\left(P_{t+1}\right)\right]^{-\epsilon}+\delta\left[1-\sigma\left(P_{t+1}\right)\right] R\left(k_{t+1}\right)\left[R\left(k_{t+1}\right) k_{t+1}\right]^{-\epsilon} \\
& -\left[w\left(k_{t}\right)-k_{t+1}\right]^{-\epsilon}=0 \\
& P_{t+1}=(1-\zeta) P_{t}+\rho k_{t} .
\end{aligned}
$$

Given $k_{0}$ and $P_{0}$ and functions $\sigma\left(P_{t+1}\right)$ and $m\left(P_{t+1}\right)$, all dynamic, competitive equilibria are characterized by sequences of $\left\{k_{t}, P_{t}, c_{t}^{y}, c_{t}^{o, d}, c_{t}^{o}\right\}$ that satisfy (11) and (12).

It is easy to check that $\partial k_{t+1} / \partial \rho>0$ along the equilibrium path. The intuition is important to lay bare. From (12), it is clear that higher $\rho$ raises the future level of pollution. Since $m^{\prime}\left(P_{t+1}\right)>0$, 
it follows that medical expenses, in the event of illness, is automatically higher. If old-age ill-health was certain, as in Gutierrez (2008), the standard life-cycle saving motive would cause agents to save more. Here the uncertainty surrounding old-age health status triggers an additional precautionary motive for saving, over and above the life-cycle motive. Both these motives work in tandem to raise aggregate saving, and hence the capital stock, which via increased capital use by firms, generates more pollution. Thus, pollution and capital accumulation reinforce each other, in part by raising medical expenses (this effect is already present in Gutierrez, 2008), and in part by raising the fraction of sick people among the elderly. As discussed in the next section, the health consequences of pollution will generally lead to lower aggregate welfare.

\subsection{Stationary Equilibrium}

Next we study how pollution affects the economy in a steady state defined by $k_{t+1}=k_{t}=\bar{k}$ and $P_{t+1}=P_{t}=\bar{P}$. (Henceforth, a bar over a variable indicates its steady-state value.) Using (11), (12), and $f(k)=A k^{\alpha}$, the steady state in a market equilibrium, $\left(\bar{k}_{m}, \bar{P}_{m}\right)$, are jointly determined by

$$
\begin{gathered}
\delta \sigma\left(\bar{P}_{m}\right) A \alpha\left(\bar{k}_{m}\right)^{\alpha-1}\left[\alpha A \bar{k}_{m}^{\alpha}-m\left(\bar{P}_{m}\right)\right]^{-\epsilon}+\delta\left[1-\sigma\left(\bar{P}_{m}\right)\right] \alpha A \bar{k}_{m}^{\alpha-1}\left(\alpha A \bar{k}_{m}^{\alpha}\right)^{-\epsilon} \\
-\left[(1-\alpha) A \bar{k}_{m}^{\alpha}-\bar{k}_{m}\right]^{-\epsilon}=0, \\
\bar{P}_{m}-\frac{\rho \bar{k}_{m}}{\zeta}=0 .
\end{gathered}
$$

Since pollution and capital accumulation are jointly and endogenously determined, it is not possible to ask questions of the form: how does capital accumulation or welfare respond to increased pollution. To get at a similar idea, we instead study the effects of a change in capital's pollution intensity, $\rho$, on capital and welfare. We assume a steady state exists. ${ }^{15}$

Proposition 2 If the steady state $\left(\bar{k}_{m}, \bar{P}_{m}\right)$ is stable, $\frac{\partial \bar{k}_{m}}{\partial \rho}>0$ and $\frac{\partial \bar{k}_{m}}{\partial \zeta}<0$.

When capital becomes more pollution-intensive (higher $\rho$ ), or when pollution dissipates more slowly (lower $\zeta$ ), both the steady state capital stock $\bar{k}_{m}$ and pollution level $\bar{P}_{m}$ increase. There is thus a positive relation between an economy's pollution intensity and its level of capital stock. Proposition 2 highlights the nature of the pollution-growth nexus: all else equal, economies with

\footnotetext{
${ }^{15}$ Palivos and Varvarigos (2011) consider multiplicity of steady states and the possibility of endogenous fluctuations around the long-run growth path. In their paper, pollution raises mortality risk; as such, higher life expectancy induces greater savings and capital accumulation which in turn increases emissions, leading to lower life expectancy and lower savings.
} 
more pollution-intensive capital and/or more slowly-dissipated pollution have higher levels of pollution and capital (and thus income) in steady states.

Even though incomes of both the old and the young rise as $\rho$ increases, the proportion of the elderly in poor health also rises. To study how changes in pollution intensity affect steady state welfare, notice

$$
\frac{\partial \bar{U}_{m}}{\partial \rho}=\frac{\partial \bar{U}_{m}}{\partial \bar{s}_{m}} \frac{\partial \bar{s}_{m}}{\partial \rho}+\left(\frac{\partial \bar{U}_{m}}{\partial \bar{w}_{m}} \frac{\partial \bar{w}_{m}}{\partial \bar{k}_{m}}+\frac{\partial \bar{U}_{m}}{\partial \bar{R}_{m}} \frac{\partial \bar{R}_{m}}{\partial \bar{k}_{m}}\right) \frac{\partial \bar{k}_{m}}{\partial \rho}+\frac{\partial \bar{U}_{m}}{\partial \bar{P}_{m}} \frac{\partial \bar{P}_{m}}{\partial \rho}
$$

Using the first order condition $\partial \bar{U}_{m} / \partial \bar{s}_{m}=0$ and the equilibrium conditions (10), (9) and (14), $\partial \bar{U}_{m} / \partial \rho$ can be simplified as

$$
\frac{\partial \bar{U}_{m}}{\partial \rho}=\underbrace{\left(R\left(\bar{k}_{m}\right)-1\right) \frac{1-\alpha}{\left(\bar{c}_{m}^{y}\right)^{-\varepsilon}} \frac{\partial \bar{k}_{m}}{\partial \rho}}_{\text {capital effect ( } \pm)}+\underbrace{\left[\frac{\partial \bar{U}_{m}}{\partial \sigma} \sigma^{\prime}\left(\bar{P}_{m}\right)+\frac{\partial \bar{U}_{m}}{\partial m} m^{\prime}\left(\bar{P}_{m}\right)\right] \frac{\partial \bar{P}_{m}}{\partial \rho}}_{\text {health effect (-) }}
$$

where $\partial \bar{P}_{m} / \partial \rho=(\rho / \zeta) \partial \bar{k}_{m} / \partial \rho+\bar{k}_{m} / \zeta>0$. An increase in $\rho$ raises pollution levels which in turn raises the risk of poor health and medical expenses in old age, all of which hurt the agent. That is, the health effect (even if $\sigma^{\prime}\left(\bar{P}_{m}\right)=0$, as in Gutierrez, 2008) is always negative. As noted before, higher pollution intensity triggers an increase in saving (capital holding). The question becomes, does additional capital accumulation help or hurt welfare? Define $\widehat{k}$ such that $R(\widehat{k}) \equiv 1$. We have

Proposition 3 If $\bar{k}_{m} \geq \widehat{k}$, an increase in the pollution intensity, $\rho$, hurts steady-state welfare. If $\bar{k}_{m}<\widehat{k}$, the capital effect in (15) is positive, and $\frac{\partial \bar{U}_{m}}{\partial \rho}$ is of ambiguous sign.

When $\bar{k}_{m} \geq \widehat{k}$, the steady state capital level is suboptimally high, and a further increase in $\bar{k}_{m}$ always reduces welfare. In this case, the capital effect and the health effect in (15) work in the same direction, and both bring long-run social welfare down. In contrast, if $\bar{k}_{m}<\widehat{k}$, more accumulation of capital may be beneficial for long-run welfare: in this case, the capital effect and the health effect have opposite welfare impacts, and the capital effect may dominate the health effect. This possibility is confirmed by the numerical example in Section 3.2 below.

Ordinarily, in a textbook Diamond (1965) model without pollution, $\widehat{k}$ would be identified as the "golden rule" and Proposition 3 would be understood as simply saying, if the economy is overaccumulating capital, any further increases in capital accumulation hurts welfare. Not so here. In Section 4 below, we show a golden rule level of $k$, the social planner's choice for $k$ that maximizes steady state welfare, is in fact lower than $\widehat{k}$ because of the pollution externality of capital. 


\subsection{An example}

Since the effect of more pollution-intensive capital (a higher $\rho$ ) is ambiguous for $\bar{k}_{m}<\widehat{k}$, we proceed to study the pollution-welfare issue via a numerical example. Our goal is to produce a reasonably well-calibrated example that illustrates the main forces at work for a typical country with high growth rates and high pollution levels, such as China. Our second goal is to show the divergence between sustainability measured in per capita GDP and that measured by utility or welfare levels when pollution is driving capital accumulation through precautionary savings.

To that end, assume each period lasts 25 years, i.e., the remaining life expectancy of an agent entering the workforce is about 50 years. The scale parameter, $A$, is set at 3 . As is more-or-less standard, let $\delta=0.99^{25}=0.78$ (see, e.g., Song (2011)) and $\epsilon=2$, which implies intertemporal elasticity of substitution of 0.5 - an intermediate value in the estimates reported in Browning, Hansen and Heckman (1999). For this parametric specification, it is easy to compute $\widehat{k}=1.127$. Next, we follow World Bank and State Environmental Protection Administration of China (2007) to choose the specification of the health risk function. We focus solely on air pollution and air pollution-caused cardiovascular and respiratory diseases, those that require hospital admissions. According to this study, $\sigma(\cdot)$ takes the functional form

$$
\sigma\left(P_{t}\right)=a+\max \left\{\exp \left[0.0019 *\left(P_{t}-15\right)\right]-1,0\right\}
$$

where $a$ is non-pollution induced health risk, $P_{t}$ is $P M_{10}$ concentration measured in the unit of $\mu \mathrm{g} / \mathrm{m}^{3}$, and 0.0019 is the health effect of $P M_{10}$ on the number of annual excess cases of hospital admissions for cardiovascular and respiratory diseases. Note that $15 \mu \mathrm{g} / \mathrm{m}^{3}$ is the threshold value of $P M_{10}$ concentration: for any lower level, $P M_{10}$ has no effect on diseases. We set $a=0.227$ so that the steady-state health risk $\sigma\left(\bar{P}_{m}\right)=0.375$ roughly matches the Chinese data. ${ }^{16}$

Finally, we assume $m_{t+1}$ to be constant and $\zeta=1$ for simplicity (allowing $\zeta<1$ or $m_{t+1}$ to increase with $P$ (or $\epsilon<1$ for that matter) would only reinforce our results). ${ }^{17}$ Letting $(\rho, \alpha, m)$ be calibrated so that the steady-state pollution $\bar{P}_{m}=88 \mu \mathrm{g} / \mathrm{m}^{3}$ and the ratio of capital investment to GDP $\bar{s}_{m} / f\left(\bar{k}_{m}\right)=0.39$ match Chinese averages between 1990 and $2008,{ }^{18}$ we obtain $(\rho, \alpha, m)=$ $(70,0.36,0.68) \cdot{ }^{19}$

\footnotetext{
${ }^{16}$ The Chinese Ministry of Health conducted three national health surveys in 1993, 1998 and 2003, and China Health Statistics Yearbook 2004 publishes the morbidity rate of chronic diseases in different age groups. By weighting the population in each group, the average morbidity rate from chronic diseases for people above age 45 is 0.375 .

${ }^{17} \zeta$ can be low for stock pollutants (e.g., lead and $C_{2}$ ), but high for flow pollutants (e.g., $P M_{10}$ or some water pollutants).

${ }^{18}$ Data source: World Development Indicators (World Bank) and China Statistical Yearbook (2010).

${ }^{19}$ The value of $\alpha$ used here is close to that estimated by Young (2003), which is 0.4.
} 


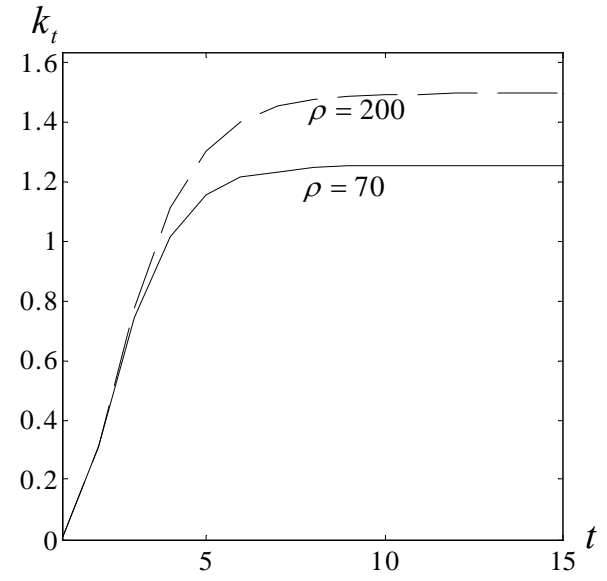

(a) Path of capital

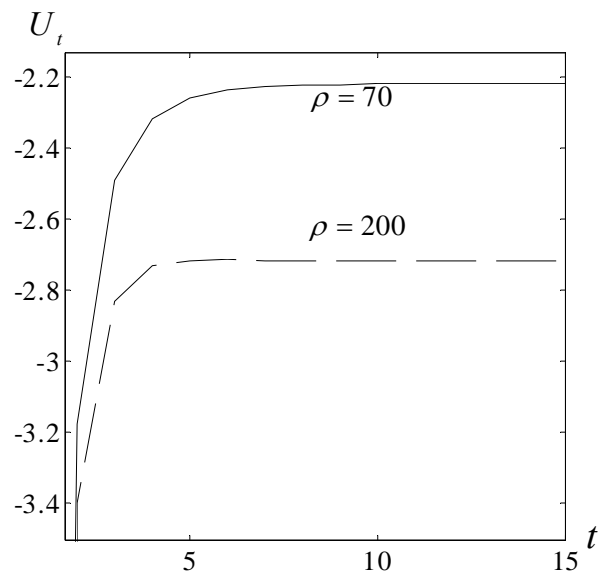

(b) Path of utility

Figure 1: Capital and utility paths for different $\rho$

In order to learn the effect of pollution on the economy, we compare our baseline case $\rho=70$ to one with $\rho=200$. Setting $k_{0}=0.01$ and $P_{0}=0$, we obtain transition paths of capital and welfare for $\rho=70$ and $\rho=200$ in Figure 1. Panel (a) is consistent with Proposition 2: higher $\rho$ implies higher capital (and thus higher pollution) levels. Panel (b) illustrates how higher $\rho$ reduces agents' lifetime utilities. When $\rho=70$, individual utilities monotonically increase over time, i.e., each generation's utility is higher than those of the previous generations, following a pattern similar to the paths for capital and pollution. But when $\rho=200$, the utilities rise for the first six periods and then starts to fall, despite $k_{t}$ increasing all along. Eventually the negative effects of pollution dominate, causing $U_{t}$ to decrease as capital and pollution further rise. The contrast between the paths of per capita capital (and thus GDP) and utility shows that an economy can seem to be on a "sustainable path" with increasing per capita GDP, but is in fact on a path with decreasing utilities.

Next we illustrate the effects of pollution intensity on the steady state capital and utility. In our baseline example, steady state utility is monotonically decreasing while capital is increasing in $\rho$. It follows from (15) that the health effect dominates the capital effect. On the other hand, when $\bar{k}_{m}$ is sufficiently low, increased pollution intensity can raise steady state utility. To illustrate this possibility, we assume a higher discount rate and low non-pollution health risk (in order to induce a low steady state capital level), by setting $\delta=0.96^{25}=0.36$ and $a=0$ (cf. (16)). ${ }^{20}$ As shown in Figure 2, although $\bar{k}_{m}$ is monotonically increasing in $\rho, \bar{U}_{m}$ may not be monotonic in $\rho$. The

\footnotetext{
${ }^{20}$ The $4 \%$ discount rate is for illustration purpose only - our baseline calibrationi uses a discount rate of $1 \%$. This combination of parameter values gives rise to an interesting case where more pollution, by raising the savings rate, can improve welfare.
} 


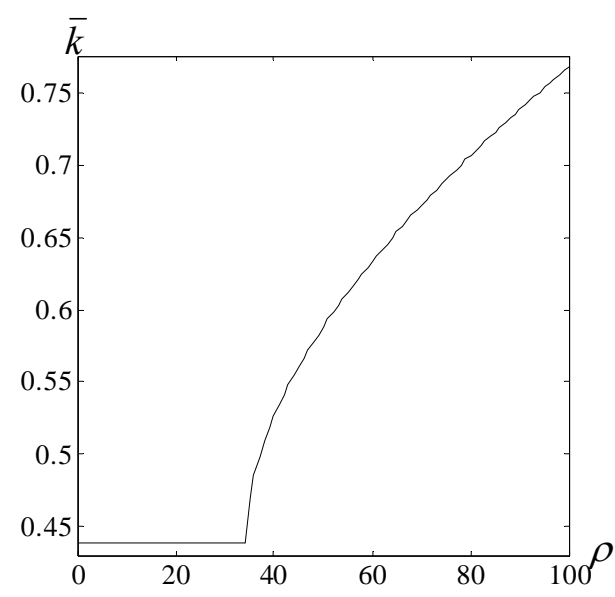

(a) Steady state capital

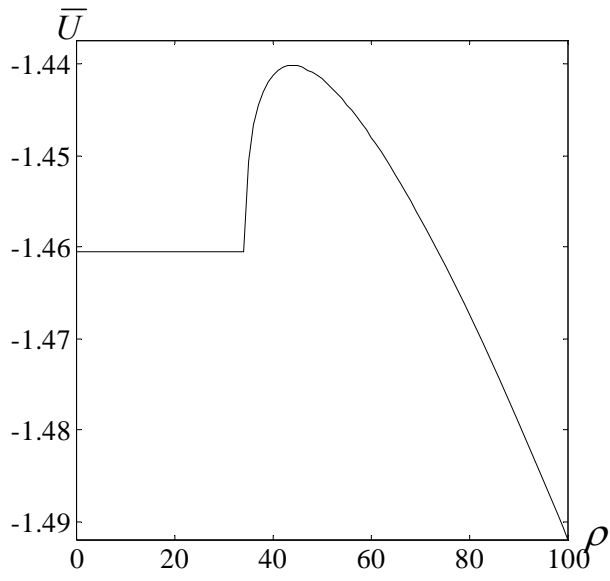

(b) Steady state utility

Figure 2: The effects of pollution intensity on steady state capital and utility

economy achieves the maximum steady state utility when $\left(\rho, \bar{k}_{m}\right)=(44,0.55)$. When $\bar{k}_{m}<0.55$, the capital effect dominates: a higher $\rho$ raises the steady state utility. ${ }^{21}$

\section{Social optimum}

Clearly, because of the public good nature of pollution (in addition to the usual possibility for dynamic inefficiency in OG models), the market equilibrium is not efficient. In this section, we characterize the steady state social optimum, where a social planner will allocate goods towards pollution abatement. Let $\bar{q}$ denote the pollution-abatement expenditure per worker. The social planner's problem is to maximize the expected lifetime utility of a representative, two-period lived generation in steady state:

$$
\max _{\left\{\bar{c}^{y}, \bar{c}^{o, d}, \bar{c}^{o}, \bar{k}, \bar{q}, \bar{P}\right\}} \frac{\left(\bar{c}^{y}\right)^{1-\epsilon}}{1-\epsilon}+\delta \frac{\sigma(\bar{P})\left(\bar{c}^{o, d}\right)^{1-\epsilon}+[1-\sigma(\bar{P})]\left(\bar{c}^{o}\right)^{1-\epsilon}}{1-\epsilon}
$$

subject to the resource constraint

$$
\bar{c}^{y}+\sigma(\bar{P})\left[\bar{c}^{o, d}+m(\bar{P})\right]+[1-\sigma(\bar{P})] \bar{c}^{o}+\bar{k}+\bar{q}=f(\bar{k})
$$

and the steady state pollution-generation function

$$
\bar{P}=\frac{\rho \bar{k}-G(\bar{q})}{\zeta}
$$

\footnotetext{
${ }^{21}$ The flat parts in Figure 2 correspond to the cases when pollution level $P_{t} \leq 15$, so that, as shown in (16), pollution has no health effects, or capital or utility effects.
} 
Solving the social planner's problem, we obtain the following necessary conditions:

$$
\begin{aligned}
& \frac{\bar{c}^{o *}}{\bar{c}^{y *}}=\delta^{\frac{1}{\epsilon}} \\
& \frac{\bar{c}^{o, d *}}{\bar{c}^{o *}}=1, \\
& f^{\prime}\left(\bar{k}^{*}\right)=1+\frac{\rho}{\zeta} D\left(\bar{P}^{*}\right), \\
& \frac{G^{\prime}\left(\bar{q}^{*}\right) D\left(\bar{P}^{*}\right)}{\zeta} \leq 1, \bar{q}^{*} \leq G^{-1}(\rho \bar{k}),\left[\frac{G^{\prime}\left(\bar{q}^{*}\right) D\left(\bar{P}^{*}\right)}{\zeta}-1\right]\left[\bar{q}^{*}-G^{-1}(\rho \bar{k})\right]=0,
\end{aligned}
$$

where

$$
D\left(\bar{P}^{*}\right) \equiv \sigma^{\prime}\left(\bar{P}^{*}\right) m\left(\bar{P}^{*}\right)+\sigma\left(\bar{P}^{*}\right) m^{\prime}\left(\bar{P}^{*}\right)
$$

is the one-period marginal damage of pollution, ${ }^{22}$ and the superscript “*” denotes socially optimal values. As is evident from $(24)$, pollution via health risk $\left(\sigma^{\prime}(\bar{P})\right)$ and medical expense $\left(m^{\prime}(\bar{P})\right)$ imposes two costs on society: (i) it increases the mass of the sick and elderly, and (ii) each such agent requires more curative medical expenditures. Since pollution $P_{t}$ in period $t$ is "inherited" (at rate $(1-\zeta)$ ) by future periods (cf. (4)), the total marginal damage equals the sum of the remaining marginal damages in all future periods, $D(\bar{P}) / \zeta$.

The left hand side of the first inequality in (23) is the marginal benefit of pollution abatement: one unit of abatement reduces per period pollution by $G^{\prime}(\bar{q})$ units, avoiding $G^{\prime}(\bar{q}) D(\bar{P}) / \zeta$ units of pollution damages from today to the distant future. The right hand side is the marginal cost of abatement, which equals one unit of consumption good. The optimality condition for an interior solution is determined by equating the marginal cost with the marginal benefit. Since $\lim _{\bar{q} \rightarrow 0} G^{\prime}(\bar{q})=\infty$, the optimal abatement $\bar{q}^{*}$ is strictly positive. However, it is possible that the marginal benefit is much larger than the marginal cost so that $\bar{q}^{*}$ takes the boundary values of abating all current pollution. This is described by the second possibility that $G\left(\bar{q}^{*}\right)=\rho \bar{k}^{*}$, which leads to $\bar{P}^{*}=0$ (cf. (19)).

Equation (22) indicates that optimal capital investment, $\bar{k}^{*}$, should incorporate the externality of pollution, measured by $\rho D(\bar{P}) / \zeta>0$. Recall from Proposition 3 that $f^{\prime}(\hat{k}) \equiv 1$. It follows that $\bar{k}^{*}$ is lower than $\hat{k}$. Thus the market economy overaccumulates capital if $\bar{k}$, the steady state capital

\footnotetext{
${ }^{22}$ The social planner's problem as stated focuses only on steady state utility of a representative two-period lived generation. An alternative would be to consider the discounted life-cycle utility of all current and future generations. The necessary conditions would be identical except that the steady-state optimal capital level is defined by $f^{\prime}(k)=$ $1 / \beta+\rho D(\bar{P}) / \zeta$ where $\beta$ is the social planner's discount rate. Our conclusions still hold true under this alternative specification.
} 
stock in market equilibrium, exceeds $\bar{k}^{*}$. In particular, the following possibility arises: $\bar{k} \geq \widehat{k}>\bar{k}^{*}$. In this case, Proposition 3 implies that an increase in pollution intensity in a market equilibrium not only hurts welfare but also worsens dynamic inefficiency.

Finally, since the agents are risk averse, the social planner - see (21) - provides complete risk sharing: old agents enjoy the same level of consumption regardless of their health status. Recall in the market solution, ill health-induced medical expenses implies a sick old agent consumes less than his healthy contemporary.

\section{$5 \quad$ Policy interventions}

There are two main inefficiencies in the market equilibrium: the lack of consumption smoothing or risk sharing for the old, and the lack of mechanisms to internalize the pollution externality of capital. In this section, we consider policy interventions that address, directly or indirectly, the two inefficiencies. We first evaluate two common stabilization instruments, private health insurance and pay-as-you-go (PAYG) insurance akin to the U.S. Medicare system. We then evaluate the effects of a Pigouvian tax as well as a set of first best policies. To highlight the two inefficiencies, we evaluate the impacts of the interventions on the steady state utility of a representative two period-lived agent. The main messages are that (i) rankings of insurance policies depend on how they affect the savings rate and thus capital and pollution accumulation, and (ii) there might exist "triple dividends" associated with pollution tax as it also affects the savings behavior.

\subsection{Health insurance}

We distinguish between two types of health insurance systems. In actuarially fair, private insurance markets, a young agent pays an insurance premium to get medical coverage when old and sick, and the insurance company invests the premiums in capital markets. Under PAYG insurance, a tax on young agents at date $t$ is used to cover the medical expenses of the sick, elderly in that same period.

\subsubsection{Private health insurance}

Suppose, in each period, competitive, zero-cost insurance companies collect premiums from the young and invest the proceeds to exactly cover medical expenses of the sick, elderly in the following 
period (and thus earn zero profit). ${ }^{23}$ Let $\theta \leq 1$ be the coverage rate, meaning the company pays $\theta m\left(P_{t+1}\right)$ to a sick, old beneficiary, and let $\theta d_{t}$ be the corresponding premium paid by the young agent (so that $d_{t}$ is the premium for one unit of coverage rate). The zero profit condition of the insurance company implies

$$
\theta d_{t} R_{t+1}=\sigma\left(P_{t+1}\right) \theta m\left(P_{t+1}\right) \Longrightarrow d_{t}=\frac{\sigma\left(P_{t+1}\right) m\left(P_{t+1}\right)}{R_{t+1}}
$$

Given the existence of the insurance market, an agent maximizes his life time utility (2) subject to the following budget constraints (cf. (5) - (7)),

$$
\begin{aligned}
& s_{t}+c_{t}^{y}+d_{t} \theta_{t+1}=w_{t} \\
& c_{t+1}^{o, d}+\left(1-\theta_{t+1}\right) m\left(P_{t+1}\right)=s_{t} R_{t+1} \\
& c_{t+1}^{o}=s_{t} R_{t+1},
\end{aligned}
$$

where $\theta_{t+1}$ measures the units of insurance purchased. The following result shows the immediate effects of private insurance before price effects (on $w$ and $R$ ) are taken into consideration.

Proposition 4 In a partial equilibrium with given $w$ and $R$, actuarially-fair private health insurance

1) implements complete risk sharing, i.e., $\theta_{t+1}=1$, and

2) reduces the agent's savings, $s_{t}$, as well as total capital accumulation, $s_{t}+d_{t}$.

The result is reminiscent of a similar result in Kotlikoff (1989) in a slightly different environment. The risk averse agent purchases full health coverage and achieves complete risk sharing: when old and if sick, the insurance pays for all his medical bills and his consumption is no longer health-state dependent. With complete risk sharing, optimal savings is given by

$$
s_{t}=\frac{w_{t}-d_{t}}{1+\delta^{-\frac{1}{\epsilon}} R_{t+1}^{1-\frac{1}{\epsilon}}} .
$$

By substituting the health insurance price in (25) to (29), we see that the agent's savings behavior is changed by the availability of health insurance: in particular, the saving is decreasing in the pollution level, $P_{t+1}$. This is in contrast to the market economy without such insurance in

\footnotetext{
${ }^{23}$ For the initial period, since the health status of the old is already revealed, health insurance is not available to them. Given this, we could study an alternative setup where we let the insurance companies spend the premiums collected in period $t$ to cover the claims of the sick, old in period $t$, and invest/borrow the remaining in the capital market. The results remain the same. To see this, note that premiums collected in period zero are invested and are just enough to cover the expected medical expenses in period one, leaving the premiums collected in period one fully invested until period two.
} 
which saving is increasing in $P_{t+1}$. Intuitively, a higher pollution level leads to increased health risk (and higher medical bills) and thus a higher price for health insurance. Since the agent's demand for health insurance is inelastic (always complete risk sharing), his premium expenditure goes up, reducing his saving.

Since the premium collected by insurance companies are invested domestically, the total saving (hence, the capital stock) consists of individual savings as well as the invested insurance premium:

$$
k_{t+1}=s_{t}+d_{t}=\frac{w_{t}+\left(\delta R_{t+1}\right)^{-\frac{1}{\epsilon}} \sigma\left(P_{t+1}\right) m\left(P_{t+1}\right)}{1+\delta^{-\frac{1}{\epsilon}} R_{t+1}^{1-\frac{1}{\epsilon}}} .
$$

Similar to the market equilibrium without insurance, the capital stock is increasing in the pollution level. Nevertheless, insurance reduces the economy wide capital stock.

Proposition 5 Availability of an actuarially-fair private health insurance system reduces the equilibrium capital stock for all time periods relative to an otherwise-identical economy with no such insurance.

Proposition 5 indicates private health insurance can help reduce the equilibrium capital stock of the economy, and via this channel, bring down pollution levels. In this sense, by achieving complete risk sharing, and consequently less capital and pollution, the provision of private health insurance can improve agents' utilities.

\subsubsection{PAYG health insurance}

Suppose, at any date, each young agent pays a lump-sum tax $g_{t}$ and each sick, elderly agent receives a coverage rate $\eta_{t}$ in the form of government payment for health expenditures. Ex-ante balancing of the government's budget at date $t$ requires

$$
\eta_{t} \sigma\left(P_{t}\right) m\left(P_{t}\right)=g_{t}
$$

An agent, taking $g_{t}$ (and the associated $\eta_{t}$ ) as given, maximizes her life time utility (2) subject to the following constraints:

$$
\begin{aligned}
& s_{t}+c_{t}^{y}=w_{t}-g_{t} \\
& c_{t+1}^{o, d}+\left(1-\eta_{t+1}\right) m\left(P_{t+1}\right)=s_{t} R_{t+1} \\
& c_{t+1}^{o}=s_{t} R_{t+1}
\end{aligned}
$$


where $\left(1-\eta_{t+1}\right) m\left(P_{t+1}\right)$ is the private, top-up medical expense over and above what is paid by the government.

Let $\bar{k}_{p}$ denote the steady state capital stock and $\bar{\eta}$ the steady state coverage rate under such a publicly-funded health scheme.

Proposition 6 In the (nontrivial) locally-stable steady state,

(i) expansion of coverage under a PAYG health insurance reduces the capital stock of the economy: $\partial \bar{k}_{p} / \partial \bar{\eta}<0$;

(ii) if the market equilibrium capital stock $\bar{k}_{p}>\widehat{k}$, steady state utility is increasing in $\bar{\eta}$.

PAYG health insurance reduces savings through two channels: first, the tax $g_{t}$ on the young reduces their disposable income, and second, public payment of expected future medical expenses $\eta_{t+1} m\left(P_{t+1}\right)$ dims the need for precautionary savings. As before, if the market economy is overaccumulating capital, then introduction of PAYG health insurance, by reducing saving as well as implementing risk sharing, unambiguously improves utility. Moreover, according to Proposition 6(ii), as long as capital is over accumulated, more ambitious PAYG system is always beneficial for the economy. That is, the government should implement complete risk sharing when $\left.\bar{k}_{p}\right|_{\bar{\eta}=1}>\widehat{k}$. It is not clear whether complete risk sharing should be implemented when $\left.\bar{k}_{p}\right|_{\bar{\eta}=1}<\widehat{k}$ where the saving-reducing effect of PAYG becomes negative. The numerical exercise below shows that full coverage of PAYG health insurance is generally not optimal.

\subsubsection{Comparison}

Both private and PAYG health insurance can help reduce the capital stock and achieve improved risk sharing. As we show below, while private health insurance achieves more risk sharing than is possible under PAYG, it turns out the latter is better at reducing the capital stock (and hence, pollution).

Proposition 7 For the same coverage rate $\theta=\eta$, the PAYG health insurance scheme reduces the equilibrium capital stock more than private health insurance does.

Figures 3 and 4 compare the steady state utilities and capital stocks in three scenarios: with no insurance, a private health insurance, and a PAYG health insurance, for different values of $\rho$, the pollution intensity of capital. In both figures, the horizontal axis is the coverage rate $\eta$ under the PAYG health insurance system, with the coverage rates (i.e., $\theta$ values) holding constant at 0 and 1 


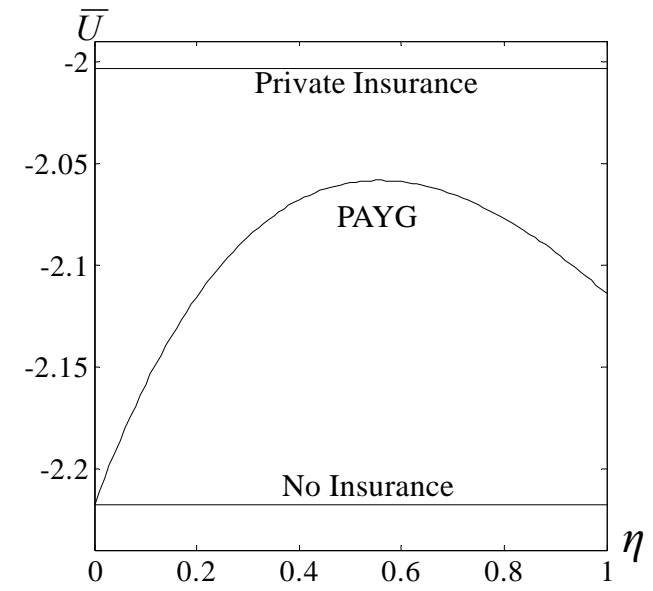

(a) $\rho=70$

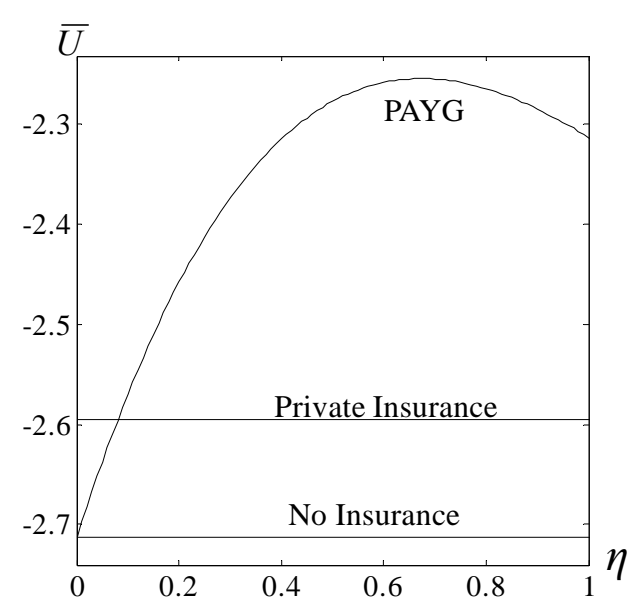

(b) $\rho=200$

Figure 3: Steady state utilities under different insurance systems

respectively for the no insurance and private insurance scenarios. Offering health insurance always improves utility. Under a PAYG insurance, the steady state utility is increasing in the coverage level $\eta$ for low values of $\eta$ (i.e., when capital stock $\bar{k}_{p}$ is high). But as the coverage is further raised, $\bar{k}_{p}$ is too low and further increases in $\eta$ reduce utility. The optimal coverage level thus involves $\eta<1$. From (33) and (34), complete risk sharing under PAYG (i.e., equal consumption levels for healthy and sick, old agents) is achieved only when $\eta=1$. Thus optimal PAYG insurance does not lead to complete risk sharing.

When the capital's pollution intensity is low $(\rho=70)$, PAYG insurance is dominated by private insurance. Since capital is not too pollution intensive, the cost due to over-accumulation of capital under private insurance is more than compensated by the benefit from complete risk sharing. However, when $\rho$ is high $(\rho=200)$, PAYG insurance at certain coverage levels can dominate private insurance: ameliorating over-accumulation of capital becomes more important when capital is more pollution intensive.

\subsection{Environmental policies}

In this subsection, we mainly address the following question: if the government can only use a pollution $\operatorname{tax} \tau$ (i.e., without any insurance policies), how will the optimal tax differ from its Pigouvian level, given that the tax might affect the savings behavior on top of the firm's abatement behavior? We show that influences on the savings rate might lead to the existence of a "triple 


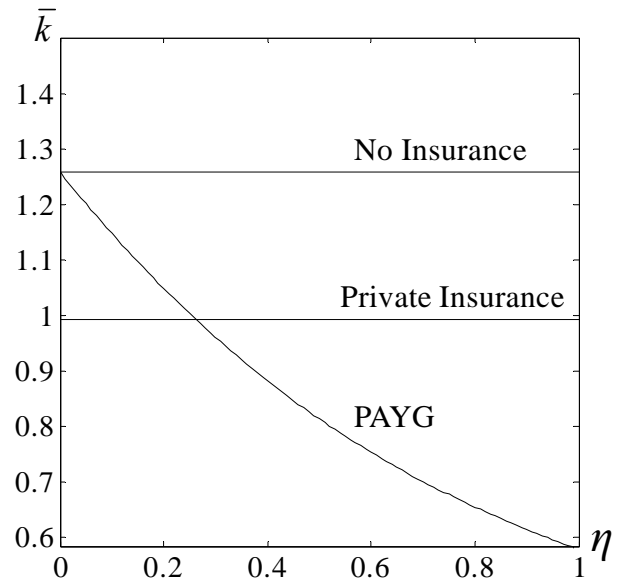

(a) $\rho=70$

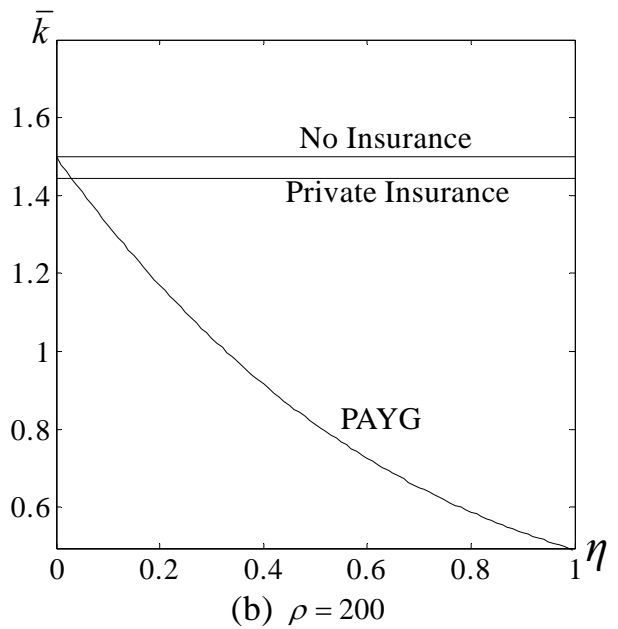

(b) $\rho=200$

Figure 4: Comparing steady state capital under different insurance systems

dividend" of the pollution tax.

Recall that a firm using capital $K$ emits pollution $\rho K$, and can reduce pollution by $G(q)$ if it chooses to spend $q$ on abatement. Facing the pollution tax, the firm's decision problem is now

$$
\max _{K_{t}, L_{t}, q_{t}} F\left(K_{t}, L_{t}\right)-R_{t} K_{t}-w_{t} L_{t}-\tau_{t}\left[\rho K_{t}-G\left(q_{t}\right)\right]-q_{t}
$$

s.t. $\quad \rho K_{t}-G\left(q_{t}\right) \geq 0$.

The optimality conditions are given by (9) and

$$
\begin{aligned}
& R_{t} \geq f^{\prime}\left(k_{t}\right)-\rho \tau_{t}, \quad R_{t}=f^{\prime}\left(k_{t}\right)-\rho \tau_{t} \quad \text { if } G\left(q_{t}\right)<\rho k_{t} ; \\
& \tau_{t} G^{\prime}\left(q_{t}\right) \geq 1,=1 \text { if } G\left(q_{t}\right)<\rho k_{t}
\end{aligned}
$$

At interior solutions (when abatement only removes part of the emissions $\rho k_{t}$ ), (36) shows that the net return on capital is reduced by the tax penalty $\rho \tau_{t}$, and in $(37), q_{t}$ is chosen to equate the marginal benefit of abatement (reduced tax expenditure), $\tau_{t} G^{\prime}\left(q_{t}\right)$, with its marginal cost of 1 .

Substituting (9) and the reduced rental rate on capital in (36) to (35), we find that the firm receives a positive profit of $\pi_{t}=\tau_{t} G\left(q_{t}\right)-q_{t}$. The source of this profit is the reduced taxation cost due to the pollution abatement activity. Given that the ownership of the firm is defined by capital, each unit of capital "earns" a share of the profit, $\pi_{t} / k_{t}$. The final return of capital is then equal to the interest rate plus this profit: $\widehat{R}_{t}=R_{t}+\pi_{t} / k_{t}$. We can show that even with the profit share, $\widehat{R}_{t}$ is still lower than capital's rate of return in the absence of the pollution tax, $f^{\prime}\left(k_{t}\right) .^{24}$

\footnotetext{
${ }^{24}$ Given $k_{t}$, the capital return, $\widehat{R}_{t}$, equals $f^{\prime}\left(k_{t}\right)+\left[\tau_{t} G\left(q_{t}\right)-\rho k_{t} \tau_{t}-q_{t}\right] / k_{t}$. Since, by the budget constraint,
} 
A major concern in the optimal emissions tax literature is how the tax revenue, $\tau_{t}\left[\rho k_{t}-G\left(q_{t}\right)\right]$, may be redistributed back to agents in the economy. Since the pollution tax is levied on firms ultimately owned by the old, we study a scenario in which the revenue is rebated back to the old in a lump-sum manner. Later we discuss implications of other ways to redistribute the revenue.

Given the capital return rate $\widehat{R}_{t}$ and the lump-sum rebate scheme, a young agent maximizes (2) subject to (5) and

$$
\begin{aligned}
& c_{t+1}^{o, d}+m\left(P_{t+1}\right)=s_{t} \widehat{R}_{t+1}+\mu_{t+1} \\
& c_{t+1}^{o}=s_{t} \widehat{R}_{t+1}+\mu_{t+1},
\end{aligned}
$$

where $\mu_{t+1} \equiv \tau_{t+1}\left[\rho k_{t+1}-G\left(q_{t+1}\right)\right]$ is the lump-sum subsidy specified above. The optimal solutions and the steady state capital and pollution levels are given in Appendix A.

We can show that the pollution tax (and the redistribution of the tax revenue) not only reduces pollution but also affects the savings behavior. It does the latter through three channels: by lowering the health risk and thus dampening precautionary savings via abatement and emission reduction; by raising old age income through subsidy $\mu_{t+1}$, and by reducing the capital return-rate, $\widehat{R}_{t+1}$. The first two channels always lower savings: the first channel is akin to the "standard" effects of a Pigouvian tax, while the second channel, arising from distribution of the tax revenue, results in a "double dividend." Since the revenue is used to subsidize incomes of the old, the tax promotes a public pension scheme, reducing the need for lifecycle savings. In fact, redistributing the pollution tax revenue to the "old and sick" is likely to be even more effective in reducing precautionary savings than the untargeted transfer to the old.

The third channel, through a lower capital return-rate, reduces saving if and only if $\epsilon<1$; this could be construed as a "triple dividend" from the pollution tax. Most analysis - see Bovenberg and De Mooj (1994) and William (2002, 2003) - of the famed "double dividend" from static models fail to show its presence in general equilibrium settings. In contrast, our results indicate that in a dynamic general equilibrium setting, appropriate distribution of the tax revenue can reduce preexisting distortions of intertemporal allocation (in household savings), and as a result, the optimal tax level can be higher than a Pigouvian tax.

We continue our numerical example of Section 3.2 to compare the optimal pollution tax in a second best setting (where the only available policy is pollution tax) to the Pigouvian tax, defined as the marginal damage, $\rho D\left(\bar{P}^{*}\right) / \zeta$ in the social planner's solution (cf. $\left.(22)\right)$. The comparison is $\overline{\rho k_{t}-G\left(q_{t}\right) \geq 0, \text { it is evident that } \widehat{R}_{t}<f^{\prime}\left(k_{t}\right)}$. 
Table 1: Steady state solutions under first and second best settings

\begin{tabular}{c|cc}
\hline & Social Planner & Second best \\
\hline$\tau$ & $1.39 \times 10^{-3}$ & $1.51 \times 10^{-3}$ \\
\hline $\bar{U}$ & -1.994 & -2.197 \\
\hline $\bar{k}$ & 0.975 & 1.174 \\
\hline $\bar{P}$ & 54.55 & 66.84 \\
\hline $\bar{q}$ & 0.0115 & 0.0139 \\
\hline
\end{tabular}

restricted to steady states. Table 1 presents the results for $\rho=70$ and $G(q)=200 \times q^{0.6}$. Given the existence of a "triple" dividend, the optimal pollution tax in the second best setting $\left(1.51 \times 10^{-3}\right)$ is higher than the corresponding Pigouvian tax $\left(1.39 \times 10^{-3}\right)$.

\subsection{Combinations of Government Policies}

Continuing the numerical example, this section studies the pairwise combinations of the above discussed policies at the steady state, where the policy levels are optimally chosen in each combination. The optimal combinations of the policies are found by maximizing the steady state utility subject to the relevant policy constraints, i.e., (25) in the case of private insurance, (31) in the case of PAYG insurance, and the tax redistribution rule in (38) and (39). For instance, the optimal combination of private and PAYG insurance systems is found by

$$
\begin{gathered}
\max _{\left\{\bar{c}^{y}, \bar{c}^{o, d}, \bar{c}^{o}, \bar{\theta}, \bar{\eta}\right\}} \frac{\left(\bar{c}^{y}\right)^{1-\epsilon}}{1-\epsilon}+\delta \frac{\sigma(\bar{P})\left(\bar{c}^{o, d}\right)^{1-\epsilon}+[1-\sigma(\bar{P})]\left(\bar{c}^{o}\right)^{1-\epsilon}}{1-\epsilon} \\
\text { s.t. } \quad \bar{s}+\bar{c}^{y}+\overline{d \theta}=\bar{w}-\bar{g} \\
\bar{c}^{o}=\bar{s} \bar{R} \\
\bar{c}^{o, d}+(1-\bar{\theta}-\bar{\eta}) m(\bar{P})=\bar{s} \bar{R}
\end{gathered}
$$

and $(25)$ and (31).

Not surprisingly, combinations of policies, properly designed, improve the agents' steady state utility compared with individual policies. Figure 5 compares the three pairwise combinations. Recall that, in Figure 3, private insurance dominates PAYG insurance for low pollution intensity $\rho=$ 70 and is dominated by optimally chosen PAYG when $\rho=200$. This welfare ordering is preserved when each insurance is combined with a pollution tax. Moreover, Figure 5 also illustrates that combining pollution tax with the private health insurance dominates (is dominated by) the other 


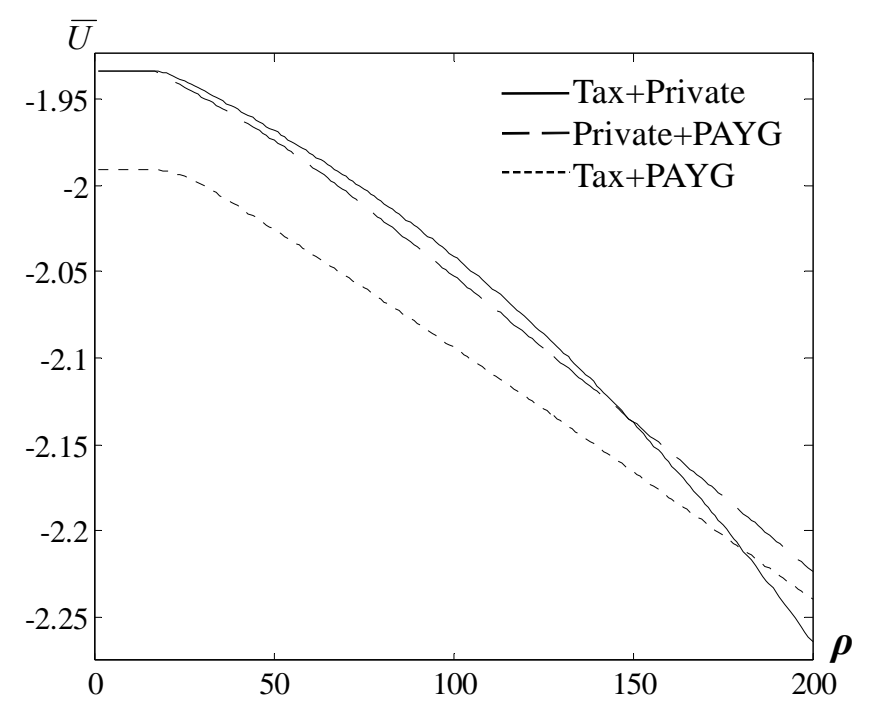

Figure 5: Steady state utilities for different policy combinations

two combinations when pollution intensity is low (high). As discussed, when pollution intensity is high so that capital and pollution are heavily over-accumulated, PAYG becomes more desirable due to its advantage in ameliorating over-accumulation of capital. Finally, we can observe that the combination of two kinds of insurance dominates the combination of tax and PAYG for all values of $\rho$ between 0 and 200 .

\section{Decentralization of the social planner's solution}

So far we have been discussing second best policies of insurance and pollution tax. In this section, we study policy instruments that can in steady state restore the first best identified in Section 4. Given that there are three distortions in the economy, namely the lack of complete risk sharing, pollution externality, and dynamic inefficiency, typically three policy instruments are needed to restore the first best. Interestingly, the combination of pollution tax, private insurance and intergenerational transfers cannot do the job. The reason is that under pollution tax, the profit generated from pollution abatement distorts the capital rate of return: while correcting one distortion, the tax creates another distortion. One more policy instrument such as a profit tax is needed to correct 
this distortion. ${ }^{25}$

In the decentralized scheme, an actuarially fair private health insurance achieves complete risk sharing for the old, a Pigouvian tax targets the pollution externality, and a profit tax removes the capital market distortion caused by the abatement profit. As is typical in OLG models, an intergenerational transfer policy is needed to solve the dynamic inefficiency problem: the government can impose a lump-sum tax on the young and make a corresponding lump-sum subsidy to the old. The next Proposition shows that PAYG health insurance can act as an intergenerational transfer mechanism.

In the case of PAYG health insurance, the balance of government budget requires, in steady state,

$$
\bar{g}+\tau \rho \bar{k}-\bar{q}=\bar{\eta} \sigma(\bar{P}) m(\bar{P})
$$

Equation (40) implies that the government uses the pollution tax and profit tax to pay for the public health insurance. This exactly shows the double-dividend role of the pollution tax and profit tax: first, the taxes are imposed to correct the externality and capital price distortion in the economy; then we can achieve the second dividend by using the tax revenue to reduce another inefficiency in the economy, namely the lack of risk sharing.

In the case of a standard intergenerational transfer scheme, the balance of government budget requires

$$
\bar{g}+\tau \rho \bar{k}-\bar{q}=\bar{\mu}
$$

where $\bar{\mu}$ is the lump-sum transfer to the old.

Proposition 8 The socially optimal solution can be decentralized in steady state by

(i) a fair health insurance,

(ii) a Pigouvian $\operatorname{tax} \tau=D\left(\bar{P}^{*}\right) / \zeta$, which equals the rate of all-period marginal damage of one unit of pollution (cf. (23)),

(iii) a profit tax at the rate of $\bar{\pi}=\tau G\left(\bar{q}^{*}\right)-\bar{q}^{*}$, and

(iv) one of the following:

(iv-1) a lump-sum transfer $\bar{\mu}=\bar{c}^{o *}-\bar{k}^{*}+\sigma\left(\bar{P}^{*}\right) m\left(\bar{P}^{*}\right)$ to the old, coupled with a lump-sum tax

\footnotetext{
${ }^{25}$ The additional distortion does not arise if we assume that the government, rather than the firm, engages in pollution abatement. However, in most cases pollution abatement is the responsibility of the polluting firms, and governments use policies to induce abatement rather than conduct abatement directly.
} 
at the rate of $\bar{\mu}+\bar{q}^{*}-\tau \rho \bar{k}^{*}$ on the young, or

(iv-2) PAYG health insurance at the coverage rate of $\bar{\eta}=1-\left(\bar{k}^{*}-\bar{c}^{o *}\right) /\left[\sigma\left(\bar{P}^{*}\right) m\left(\bar{P}^{*}\right)\right]$, coupled with a lump-sum tax at the rate of $\bar{\eta} \sigma\left(\bar{P}^{*}\right) m\left(\bar{P}^{*}\right)+\bar{q}^{*}-\tau \rho \bar{k}^{*}$ on the young.

Proposition 8(iv) shows that the intergenerational transfer can be "implemented" by the PAYG insurance. Continuing the numerical example in the previous section, the optimal policies that can replicate the socially optimal allocation include $\bar{\theta}=1$ (full private insurance), $\tau=0.0014, \bar{g}=$ -0.017 , and $\bar{\eta}=0.3215$ in the case of PAYG insurance or $\bar{\mu}=0.0667$ in the case of intergenerational transfer.

\section{Conclusion}

In this paper, we study the pollution-growth nexus and how it impacts on societal welfare. We construct an OG model in which agents save more in response to pollution-induced health risk, and the increased savings lead to more capital investment and more pollution. Such an economy may experience high economic activity coupled with high pollution levels. However, welfare will suffer along such a growth path.

Our work points to the fact that health, capital accumulation and pollution are intertwined and evolve endogenously and interconnectedly in a growing economy; as such, policy interventions in one arena necessarily spillover into others. We consider three kinds of policy interventions to "break" the pollution-growth-pollution cycle: private insurance, pay-as-you-go insurance, and a tax on pollution. In a general equilibrium setting, insurance policies influence pollution levels and thus have environmental effects. Conversely, environmental policies affect saving and health risks, and thus have stabilization implications. The three kinds of policies help correct the distortions in the economy: private insurance achieves full risk sharing but may not sufficiently reduce the total investment or the pollution level; PAYG insurance reduces investment and pollution but can only achieve partial risk sharing; and a pollution tax reduces pollution and saving, but causes an additional distortion in capital's rate of return. An additional policy instrument is needed to restore the first best. The stabilization benefit of the pollution tax partly depends on how the tax revenue is distributed. This benefit arises only in a dynamic setting. That is, even when double dividends do not exist in a static setting, they can still arise in a dynamic setting through the effect on saving behavior.

The environmental objectives are best served in a system with intergenerational transfers from 
the young to the old (especially the old who are sick). From this perspective, pay-as-you-go schemes (at properly chosen levels) can be more desirable than schemes with private accounts (e.g., private insurance or private retirement accounts). Since PAYG schemes can never achieve full risk sharing, they should be supplemented by private health insurance. Given the existence of (dynamic) double dividends of the pollution tax, the optimal pollution tax should be higher than the Pigouvian level. Further, the tax revenue should be redistributed to serve a "stabilization purpose". The most desirable approach is to redistribute the revenue to the old and sick, e.g., as contributions to premiums in a PAYG scheme.

The findings in this paper have important implications for developing nations such as China and India that are experiencing rapid economic growth alongside steady environmental degradation. Our paper suggests that even when high levels of economic activity in these countries appear attractive, they may not be desirable from a welfare standpoint due to the adverse health outcomes. More importantly, the lack of adequate health care and social security institutions in these countries may have inadvertently contributed to the pollution-growth-pollution cycle. This observation highlights the urgency of developing such institutions and the necessity of incorporating environmental objectives in doing so.

\section{Appendix A: Technical Details}

Proof of Proposition 1. Applying the implicit function theorem to (8), we have

$$
\frac{\partial s_{t}}{\partial P_{t+1}}=-\frac{\delta R_{t+1}\left[\left(c_{t+1}^{o, d}\right)^{-\epsilon}-\left(c_{t+1}^{o}\right)^{-\epsilon}\right] \sigma^{\prime}\left(P_{t+1}\right)+\frac{\epsilon \delta \sigma_{t+1} R_{t+1}}{\left(c_{t+1}^{o, d}\right)^{\epsilon+1}} m^{\prime}\left(P_{t+1}\right)}{\frac{\partial^{2} U_{t}}{\partial s_{t}^{2}}}
$$

By concavity of the utility function, $\partial^{2} U_{t} / \partial s_{t}^{2}<0$, and hence $\frac{\partial s_{t}}{\partial P_{t+1}}>0$, for all $\epsilon>0$.

Proof of Proposition 2. By linearizing around the steady state, we have

$$
\left(\begin{array}{c}
k_{t+1}-\bar{k}_{m} \\
P_{t+1}-\bar{P}_{m}
\end{array}\right)=\left(\begin{array}{cc}
-\frac{\epsilon \alpha(1-\alpha) A \bar{k}_{m}^{\alpha-1}\left[(1-\alpha) A \bar{k}_{m}^{\alpha}-\bar{k}_{m}\right]^{-\epsilon-1}}{C} & -\frac{B}{C} \\
\rho & 1-\zeta
\end{array}\right) *\left(\begin{array}{c}
k_{t}-\bar{k}_{m} \\
P_{t}-\bar{P}_{m}
\end{array}\right)
$$

where

$$
B \equiv \delta \alpha A \bar{k}_{m}^{\alpha-1}\left\{\left\{\left[\alpha A \bar{k}_{m}^{\alpha}-m\left(\bar{P}_{m}\right)\right]^{-\epsilon}-\left(\alpha A \bar{k}_{m}^{\alpha}\right)^{-\epsilon}\right\} \sigma^{\prime}\left(\bar{P}_{m}\right)+\frac{\epsilon \sigma\left(\bar{P}_{m}\right) m^{\prime}\left(\bar{P}_{m}\right)}{\left[\alpha A \bar{k}_{m}^{\alpha}-m\left(\bar{P}_{m}\right)\right]^{\epsilon+1}}\right\}>0
$$


and

$$
\begin{aligned}
& C \equiv-\left[(1-\alpha)^{2} A \bar{k}_{m}^{\alpha-1}-1+\alpha+\epsilon\right]\left[(1-\alpha) A \bar{k}_{m}^{\alpha}-\bar{k}_{m}\right]^{-\epsilon-1} \\
& -\epsilon \delta \alpha^{3} A^{2} \bar{k}_{m}^{2 \alpha-2}\left\{\sigma\left(\bar{P}_{m}\right)\left[\alpha A \bar{k}_{m}^{\alpha}-m\left(\bar{P}_{m}\right)\right]^{-\epsilon-1}+\left[1-\sigma\left(\bar{P}_{m}\right)\right]\left(\alpha A \bar{k}_{m}^{\alpha}\right)^{-\epsilon-1}\right\}
\end{aligned}
$$

Since $(1-\alpha) A \bar{k}_{m}^{\alpha}-\bar{k}_{m}>0$, we must have $(1-\alpha)^{2} A \bar{k}_{m}^{\alpha-1}-1+\alpha>0$ and therefore $C<0$.

The steady state is locally stable if and only if

$$
D-T+1=\frac{\rho B+\zeta \epsilon \alpha(1-\alpha) A \bar{k}_{m}^{\alpha-1}\left[(1-\alpha) A \bar{k}_{m}^{\alpha}-\bar{k}_{m}\right]^{-\epsilon-1}}{C}+\zeta>0
$$

and

$$
D+T+1=2-\zeta+\frac{\rho B-(2-\zeta) \epsilon \alpha(1-\alpha) A \bar{k}_{m}^{\alpha-1}\left[(1-\alpha) A \bar{k}_{m}^{\alpha}-\bar{k}_{m}\right]^{-\epsilon-1}}{C}>0
$$

where $D$ and $T$ refer to the determinant and trace of the Jacobian matrix. Evidently $D+T+1>$ $D-T+1$. Therefore, by defining $E\left(\bar{k}_{m}, \bar{P}_{m}\right) \equiv D-T+1, E\left(\bar{k}_{m}, \bar{P}_{m}\right)>0$ is sufficient to ensure the stability of the steady state. This implies

$$
\rho B+\zeta \epsilon \alpha(1-\alpha) A \bar{k}_{m}^{\alpha-1}\left[(1-\alpha) A \bar{k}_{m}^{\alpha}-\bar{k}_{m}\right]^{-\epsilon-1}+\zeta C<0
$$

holds. Substituting (14) into (13) and applying the implicit function theorem yields

$$
\frac{\partial \bar{k}_{m}}{\partial \rho}=-\frac{B \bar{k}_{m}}{\zeta C+\zeta \epsilon(1-\alpha) \alpha A \bar{k}_{m}^{\alpha-1}\left[(1-\alpha) A \bar{k}_{m}^{\alpha}-\bar{k}_{m}\right]^{-\epsilon-1}}
$$

Since $E\left(\bar{k}_{m}, \bar{P}_{m}\right)>0$ is assumed to be true and $C<0$, it follows that $\partial \bar{k}_{m} / \partial \rho>0$.

Proof of Proposition 4. 1) Agent's optimal choice of $\theta$ is determined by the following Kuhn-Tucker condition

$$
\frac{\partial U_{t}}{\partial \theta_{t+1}} \geq 0,\left(1-\theta_{t+1}\right) \frac{\partial U_{t}}{\partial \theta_{t+1}}=0
$$

where

$$
\frac{\partial U_{t}}{\partial \theta_{t+1}}=\delta \sigma\left(P_{t+1}\right) m\left(P_{t+1}\right)\left(c_{t+1}^{o, d}\right)^{-\epsilon}-d_{t}\left(c_{t}^{y}\right)^{-\epsilon} .
$$

Therefore, $\theta_{t+1}=1$ if and only if $\partial U_{t} / \partial \theta_{t+1}>0$ for all $\theta_{t+1}<1$. Substituting in the insurance premium in $(25)$, we obtain

$$
\frac{\partial U_{t}}{\partial \theta_{t+1}}=\frac{\sigma\left(P_{t+1}\right) m\left(P_{t+1}\right)}{R_{t+1}}\left[\delta R_{t+1}\left(c_{t+1}^{o, d}\right)^{-\epsilon}-\left(c_{t}^{y}\right)^{-\epsilon}\right]
$$


Hence we only need to prove $\delta R_{t+1}\left(c_{t+1}^{o, d}\right)^{-\epsilon}-\left(c_{t}^{y}\right)^{-\epsilon}>0$ for all $\theta_{t+1}<1$.

Since $s_{t}$ has interior solution, we can get

$$
\frac{\partial U_{t}}{\partial s_{t}}=\delta R_{t+1}\left\{\left[1-\sigma\left(P_{t+1}\right)\right]\left(c_{t+1}^{o}\right)^{-\epsilon}+\sigma\left(P_{t+1}\right)\left(c_{t+1}^{o, d}\right)^{-\epsilon}\right\}-\left(c_{t}^{y}\right)^{-\epsilon}=0
$$

Since $c_{t+1}^{o}>c_{t+1}^{o, d}$ for $\theta_{t+1}<1$, we must have

$$
\left[1-\sigma\left(P_{t+1}\right)\right]\left(c_{t+1}^{o}\right)^{-\epsilon}+\sigma\left(P_{t+1}\right)\left(c_{t+1}^{o, d}\right)^{-\epsilon}<\left(c_{t+1}^{o, d}\right)^{-\epsilon},
$$

and thus

$$
\left(c_{t}^{y}\right)^{-\epsilon}<\delta R_{t+1}\left(c_{t+1}^{o, d}\right)^{-\epsilon}
$$

which proves part 1 of the Proposition.

2 ) Denote $\widetilde{s}_{t}$ agent's optimal savings in the case of private health insurance. $\widetilde{s}_{t}$ is determined by (42). Since we have shown in part 1 that $\theta_{t+1}$ equals to 1 , (42) can be written as

$$
\delta R_{t+1}\left[\left(\widetilde{S}_{t}-d_{t}\right) R_{t+1}\right]^{-\epsilon}=\left(w_{t}-\widetilde{S}_{t}\right)^{-\epsilon}
$$

where $\widetilde{S}_{t}=\widetilde{s}_{t}+d_{t}$ is total savings in the economy. Let $\widehat{s}_{t}$ be the optimal savings in the benchmark case solved by equation (8). To prove part 2 , it is enough to show $\widetilde{S}_{t}<\widehat{s}_{t}$.

Using (25), (43) can be further rewritten as

$$
\delta R_{t+1}\left[\widetilde{S}_{t} R_{t+1}-\sigma\left(P_{t+1}\right) m\left(P_{t+1}\right)\right]^{-\epsilon}=\left(w_{t}-\widetilde{S}_{t}\right)^{-\epsilon}
$$

Then by defining functions $F(x)=\left(w_{t}-x\right)^{-\epsilon}, H^{1}(x)=\delta R_{t+1}\left[x R_{t+1}-\sigma\left(P_{t+1}\right) m\left(P_{t+1}\right)\right]^{-\epsilon}$ and $H^{2}(x)=\delta R_{t+1}\left\{\sigma_{t+1}\left[x R_{t+1}-m\left(P_{t+1}\right)\right]^{-\epsilon}+\left(1-\sigma_{t+1}\right)\left(x R_{t+1}\right)^{-\epsilon}\right\}$, we know $\widehat{s}_{t}$ is the intersection point between $F(x)$ and $H^{2}(x)$, and $\widetilde{S}_{t}$ is the intersection point between $F(x)$ and $H^{1}(x)$. Since $F(x)$ is increasing and convex in $x$ and $H^{1}(x)$, as well as $H^{2}(x)$, is decreasing and convex in $x$, to prove part 2, we only need to show curve $H^{1}(x)$ is always below curve $H^{2}(x)$ as illustrated in Figure 6 . By the convexity of function, $(\cdot)^{-\epsilon}$, we have

$$
\left[x R_{t+1}-\sigma_{t+1} m\left(P_{t+1}\right)\right]^{-\epsilon}<\sigma_{t+1}\left[x R_{t+1}-m\left(P_{t+1}\right)\right]^{-\epsilon}+\left(1-\sigma_{t+1}\right)\left(x R_{t+1}\right)^{-\epsilon}
$$

Therefore $H^{1}(x)<H^{2}(x)$ for all $x$, establishing part 2 .

\section{Proof of Proposition 5.}

The equilibrium sequence $\left\{k_{t}, P_{t}\right\}_{t=0}^{\infty}$ satisfies (12) and

$$
\delta \alpha A k_{t+1}^{\alpha-1}\left[\alpha A k_{t+1}^{\alpha}-\sigma\left(P_{t+1}\right) m\left(P_{t+1}\right)\right]^{-\epsilon}-\left[(1-\alpha) A k_{t}^{\alpha}-k_{t+1}\right]^{-\epsilon}=0 .
$$




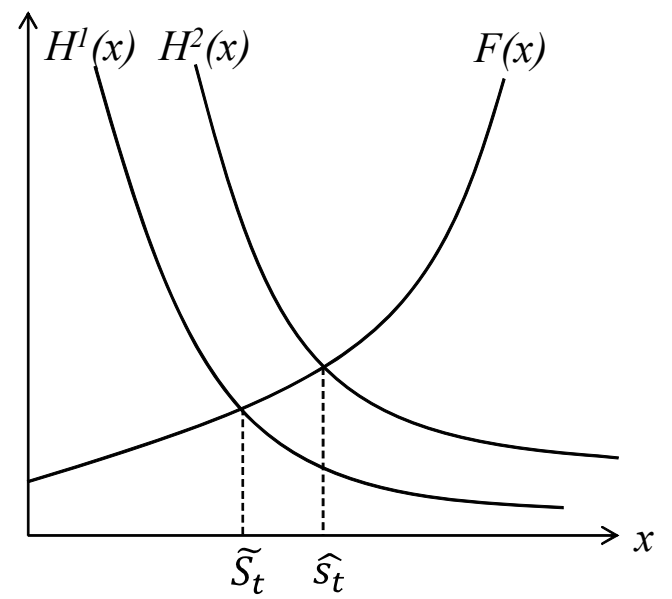

Figure 6: Proof of $\tilde{S}_{t}<\hat{s}_{t}$

Some rearrangement of the equilibrium condition in the benchmark case (11) leads to

$$
\begin{aligned}
\delta \sigma_{t+1} \alpha A k_{t+1}^{\alpha-1}\left[\alpha A k_{t+1}^{\alpha}-m\left(P_{t+1}\right)\right]^{-\epsilon} & +\delta\left(1-\sigma_{t+1}\right) \alpha A k_{t+1}^{\alpha-1}\left(\alpha A k_{t+1}^{\alpha}\right)^{-\epsilon} \\
& =\left[(1-\alpha) A k_{t}^{\alpha}-k_{t+1}\right]^{-\epsilon}
\end{aligned}
$$

As for the equilibrium condition in the case of private health insurance (45), we have

$$
\delta \alpha A k_{t+1}^{\alpha-1}\left[\alpha A k_{t+1}^{\alpha}-\sigma\left(P_{t+1}\right) m\left(P_{t+1}\right)\right]^{-\epsilon}=\left[(1-\alpha) A k_{t}^{\alpha}-k_{t+1}\right]^{-\epsilon}
$$

Obviously, given $P_{t+1}$, the right hand side of (46) and (47) is convex and increasing in $k_{t+1}$, and the left hand side of (46) and (47) decreases in $k_{t+1}$. In addition, for any $k_{t+1}$, the left hand side of (47) is always less than that of (46) due to the convexity of function, $(\cdot)^{-\epsilon}$. Hence given $P_{t+1}, k_{t+1}$ solved by (47) is less than that solved by (46). On the other side, from (11) and (45), we know $k_{t+1}$ is increasing in $P_{t+1}$ for both cases. Therefore for a given initial $\left(k_{0}, P_{0}\right)$, the equilibrium $\left(k_{t}, P_{t}\right)$, $\forall t>0$, in the economy with private health insurance should be less than that in the benchmark case. This completes the proof.

Proof of Proposition 6. 1) This part resembles the proof of Proposition 2. Using the agent's first order conditions, we can show that in the nontrivial steady state with constant coverage rate $\bar{\eta}$, the capital level $\bar{k}_{p}$ is determined by

$$
\begin{aligned}
& J=\delta \alpha A \bar{k}_{p}^{\alpha-1}\left\{\sigma\left(\bar{P}_{p}\right)\left[\alpha A \bar{k}_{p}^{\alpha}-(1-\bar{\eta}) m\left(\bar{P}_{p}\right)\right]^{-\epsilon}+\left[1-\sigma\left(\bar{P}_{p}\right)\right]\left(\alpha A \bar{k}_{p}^{\alpha}\right)^{-\epsilon}\right\} \\
& -\left[(1-\alpha) A \bar{k}_{p}^{\alpha}-\bar{k}_{p}-\bar{\eta} \sigma\left(\bar{P}_{p}\right) m\left(\bar{P}_{p}\right)\right]^{-\epsilon}=0
\end{aligned}
$$


Substituting (14) into (48) and applying the implicit function theorem can yield

$$
\frac{\partial \bar{k}_{p}}{\partial \bar{\eta}}=-\frac{-\epsilon m\left(\bar{P}_{p}\right) \sigma\left(\bar{P}_{p}\right)\left\{\delta \alpha A \bar{k}_{p}^{\alpha-1}\left[\alpha A \bar{k}_{p}^{\alpha}-m\left(\bar{P}_{p}\right)\right]^{-\epsilon-1}+\left[(1-\alpha) A \bar{k}_{p}^{\alpha}-\bar{k}_{p}\right]^{-\epsilon-1}\right\}}{\partial J / \partial \bar{k}_{p}}
$$

Following the same argument in the proof of Proposition 2, we can show that $\partial J / \partial \bar{k}_{p}<0$ at the stable steady state and therefore $\partial \bar{k}_{p} / \partial \bar{\eta}<0$.

2) Taking derivative of $\bar{U}_{p}$ with respect to $\bar{\eta}$ and substituting the agent's first order conditions, equilibrium conditions (10), (9), and (14) into $\partial \bar{U}_{p} / \partial \bar{\eta}$, we have

$$
\begin{aligned}
\frac{\partial \bar{U}_{p}}{\partial \bar{\eta}}= & \left(\bar{R}_{p}-1\right) \frac{1-\alpha}{\left(\bar{c}_{p}^{y}\right)^{-\epsilon}} \frac{\partial \bar{k}_{p}}{\partial \bar{\eta}}+\frac{\rho}{\zeta} \frac{\partial \bar{U}_{p}}{\partial \bar{P}_{p}} \frac{\partial \bar{k}_{p}}{\partial \bar{\eta}} \\
& +\delta \sigma\left(\bar{P}_{p}\right) m\left(\bar{P}_{p}\right)\left[\left[1-\sigma\left(\bar{P}_{p}\right) \bar{R}_{p}\right]\left(\bar{c}_{p}^{o, d}\right)^{-\epsilon}-\bar{R}\left[1-\sigma\left(\bar{P}_{p}\right)\right]\left(\bar{c}_{p}^{o}\right)^{-\epsilon}\right]
\end{aligned}
$$

Since $\partial \bar{k}_{p} / \partial \bar{\eta}<0$ and $\partial \bar{U} / \partial \bar{P}_{p}<0$, if $\bar{k}_{p} \geq \widehat{k}$, i.e. $\bar{R}_{p}<1$, the steady-state utility is monotonically increasing in $\bar{\eta}$, i.e., $\partial \bar{U}_{p} / \partial \bar{\eta}>0$.

Proof of Proposition 7. Given $\theta$, the equilibrium capital investment in the case of private health insurance is determined by

$$
\delta \alpha A k_{t+1}^{\alpha-1}\left\{\begin{array}{c}
\sigma\left(P_{t+1}\right)\left[\alpha A k_{t+1}^{\alpha}-\sigma\left(P_{t}\right) m\left(P_{t}\right) \theta_{t+1}-(1-\theta) m\left(P_{t}\right)\right]^{-\epsilon} \\
+\left[1-\sigma\left(P_{t+1}\right)\right]\left[\alpha A k_{t+1}^{\alpha}-\sigma\left(P_{t}\right) m\left(P_{t}\right) \theta_{t+1}\right]^{-\epsilon}
\end{array}\right\}=\left[(1-\alpha) A k_{t}^{\alpha}-k_{t+1}\right]^{-\epsilon}
$$

and that in the case of PAYG given $\eta$ is determined by

$$
\delta \alpha A k_{t+1}^{\alpha-1}\left\{\begin{array}{c}
\sigma\left(P_{t+1}\right)\left[\alpha A k_{t+1}^{\alpha}-(1-\eta) m\left(P_{t+1}\right)\right]^{-\epsilon} \\
+\left[1-\sigma\left(P_{t+1}\right)\right]\left(\alpha A k_{t+1}^{\alpha}\right)^{-\epsilon}
\end{array}\right\}=\left[(1-\alpha) A k_{t}^{\alpha}-k_{t+1}-\eta \sigma\left(P_{t}\right) m\left(P_{t}\right)\right]^{-\epsilon}
$$

The right hand sides of (49) and (50) are convex and increasing in $k_{t+1}$, and the left hand side of (49) and (50) decrease in $k_{t+1}$. In addition, for any $k_{t+1}$ and given $\theta=\eta$, the left (right) hand side of (50) is less (larger) than that of (49). Hence $k_{t+1}$ solved by (50) is less than that solved by (49), which completes the proof.

Optimal solutions under pollution tax. Using (38) and (39), we know that at an optimum, the young agent's savings decision is given by

$$
\left(w_{t}-s_{t}\right)^{-\epsilon}=\delta \widehat{R}_{t+1}\left\{\sigma_{t+1}\left[s_{t} \widehat{R}_{t+1}+\mu_{t+1}-m\left(P_{t+1}\right)\right]^{-\epsilon}+\left(1-\sigma_{t+1}\right)\left(s_{t} \widehat{R}_{t+1}+\mu_{t+1}\right)^{-\epsilon}\right\}
$$


The steady state is described by

$$
\begin{aligned}
& {\left[(1-\alpha) A \bar{k}^{\alpha}-\bar{k}\right]^{-\epsilon}=\delta \bar{R}\left\{\sigma(\bar{P})[\overline{k R}+\bar{\mu}-m(\bar{P})]^{-\epsilon}+[1-\sigma(\bar{P})](\overline{k R}+\bar{\mu})^{-\epsilon}\right\}} \\
& \bar{P}=\frac{\rho \bar{k}-G(\bar{q})}{\zeta}
\end{aligned}
$$

where $\bar{\mu} \equiv \tau[\rho \bar{k}-G(\bar{q})]$ and $\bar{R}=f^{\prime}(\bar{k})-\rho \tau+\bar{\pi} / \bar{k}=f^{\prime}(\bar{k})-\bar{q}$.

Proof of Proposition 8. 1) When the intergenerational transfer consists of lump-sum tax on the young and lump-sum subsidy on the old, the agent's problem is

$$
\max _{\left\{\bar{c}^{y}, \bar{c}^{o, d}, \bar{c}^{o}, \bar{s}, \bar{\theta}\right\}} \frac{\left(\bar{c}^{y}\right)^{1-\epsilon}}{1-\epsilon}+\delta \frac{\sigma(\bar{P})\left(\bar{c}^{o, d}\right)^{1-\epsilon}+[1-\sigma(\bar{P})]\left(\bar{c}^{o}\right)^{1-\epsilon}}{1-\epsilon}
$$

subject to

$$
\begin{aligned}
\bar{s}+\bar{c}^{y}+\overline{d \theta} & =\bar{w}-\bar{g} \\
\bar{c}^{o, d}+(1-\bar{\theta}) m(\bar{P}) & =\bar{s} \bar{R}+\bar{\mu} \\
\bar{c}^{o} & =\bar{s} \bar{R}+\bar{\mu}
\end{aligned}
$$

The agent's first order condition (in term of $\bar{s}$ ) is

$$
\left(\bar{c}^{y}\right)^{-\epsilon}=\delta \bar{R}\left[\sigma(\bar{P})\left(\bar{c}^{o, d}\right)^{-\epsilon}+[1-\sigma(\bar{P})]\left(\bar{c}^{o}\right)^{-\epsilon}\right]
$$

As shown in Proposition 4, agent would buy full coverage rate under private health insurance system, i.e. $\bar{\theta}=1$. Hence (57) could be simplified to

$$
\left(\bar{c}^{y}\right)^{-\epsilon}=\delta \bar{R}\left(\bar{c}^{o}\right)^{-\epsilon}
$$

Since firm's problem is same as in the section of environmental policies, imposing Pigouvian $\operatorname{tax} \tau=D\left(\bar{P}^{*}\right) / \zeta$ achieves social planner's solutions (22) and (23). In addition, the private health insurance system guarantees full risk sharing and thus achieves the social planner's solution (21). Finally, comparison of (58) to social planner's solution (20) implies that, to decentralize the social optimum, we only need to optimally choose $\bar{\mu}$ and $\bar{g}$ so that $\bar{R}=1$. We solve $\bar{\mu}$ and $\bar{g}$ in the following.

As afore-discussed, the capital investment consists of individual savings and premium of private health insurance. That implies when $\bar{\mu}$ is optimally chosen, the individual savings are defined by

$$
\bar{s}=\bar{k}^{*}-\overline{d \theta}=\bar{k}^{*}-\sigma\left(\bar{P}^{*}\right) m\left(\bar{P}^{*}\right)
$$


Then when the social optimum is successfully decentralized, (56) should become

$$
\bar{c}^{o *}=\bar{s} \bar{R}+\bar{\mu}=\bar{k}^{*}-\sigma\left(\bar{P}^{*}\right) m\left(\bar{P}^{*}\right)+\bar{\mu}
$$

which solves $\bar{\mu}$. The value of $\bar{g}$ follows directly from (41).

2) When the intergenerational transfer consists of lump-sum tax on the young and PAYG health insurance, the agent's budget constraints change to (54) and

$$
\begin{aligned}
\bar{c}^{o, d}+(1-\bar{\theta}-\bar{\eta}) m(\bar{P}) & =\bar{s} \bar{R} \\
\bar{c}^{o} & =\bar{s} \bar{R}
\end{aligned}
$$

As in the proof of part (1), agent buys full coverage rate of health insurance $\bar{\theta}=1-\bar{\eta}$, (57) holds and we need to optimally choose $\bar{\eta}$ and $\bar{g}$ to guarantee $\bar{R}=1$. To derive $\bar{\eta}$ and $\bar{g}$, we still use the equilibrium condition $\bar{k}^{*}=\bar{s}+\overline{d \theta}$. By the new budget constraint, when $\bar{R}=1, \bar{s}=\bar{c}^{o}$. Hence when $\bar{\eta}$ is optimally chosen, we should have

$$
\bar{k}^{*}=\bar{s}+\overline{d \theta}=\bar{c}^{o *}+\bar{\theta} \sigma\left(\bar{P}^{*}\right) m\left(\bar{P}^{*}\right)
$$

from which we could solve $\bar{\theta}$ as well as optimal $\bar{\eta}$

$$
\bar{\eta}=1-\bar{\theta}=1-\left(\bar{k}^{*}-\bar{c}^{o *}\right) / \sigma\left(\bar{P}^{*}\right) m\left(\bar{P}^{*}\right)
$$

The value of $\bar{g}$ follows directly from (41).

\section{References}

Bovenberg, A. Lans and De Mooij, Ruud A. (1994), Environmental Levies and Distortionary Taxation, American Economic Review 84(4), 1085-1089.

Bovenberg, A. Lans and Smulders, Sjak (1995), Environmental Quality and Pollution-Augmenting Technological Change in A Two-sector Endogenous Growth Model, Journal of Public Economics 57, 369-391.

Bovenberg, A. Lans and Smulders, Sjak (1996), Transitional Impacts of Environmental Policy in An Endogenous Growth Model, International Economic Review 37(4), 861-893.

Browning, Martin, Hansen, P. Lars and Heckman, J. James (1999), Microdata and General Equilibrium Models, in John B. Taylor and Michale Woodford (eds.), Handbook of Macroeconomics, vol. 1, Amsterdam: Elsevier Science. 
Brunekreef, Bert and Stephen T. Holgate (2002), Air Pollution and Health, Lancet 360, 1233-1242.

Chamon, Marcos and Prasad, Eswar (2010), Why are Saving Rates of Urban Households in China Rising? American Economic Journal: Macroeconomics 2(1), 93-130.

Daniels, Michael et al. (2000), Estimating Particulate Matter-Mortality Dose-Response Curves and Threshold Levels: An Analysis of Daily Time-Series for the 20 Largest US Cities, American Journal of Epidemiology 152(5), 397-406.

Diamond, P. A. (1965), National Debt in a Neoclassical Growth Model, American Economic Review 55, 1126-1150.

Dockery, D.W., et al. (1993), An Association between Air Pollution and Mortality in Six U.S. Cities, New England Journal of Medicine 329(24), 1753-1759.

Evans, M. F., and Smith, V. K., (2005), Do New Health Conditions Support Mortality-Air Pollution Effects, Journal of Environmental Economics and Management 50(3), 496-518.

Goenka, A., Jafarey, S. \& Pouliot, W. (2012). Pollution, mortality and optimal environmental policy (Report No. 12/07). London, UK: Department of Economics, City University London.

Gradus, Raymond and Smulders, Sjak (1993), The Trade-off between Environmental Care and Long-term Growth - Pollution in Three Prototype Growth Models, Journal of Economics $58(1), 25-51$.

Gruver, G.W. (1976), Optimal Investment in Pollution Control Capital in a Neoclassical Growth Context, Journal of Environmental Economics and Management 5, 165-177.

Gutierrez, Maria J. (2008), Dynamic Inefficiency in An Overlapping Generation Economy with Pollution and Health Costs, Journal of Public Economic Theory.

John, A. and Pecchenino, R. (1994), An Overlapping Generations Model of Growth and the Environment, The Economic Journal 104, 1393-1410.

John, A., Pecchenino, R., Schimmelpfennig, D., and Schreft, S. (1995), Short-lived Agents and the Long-lived Environment, Journal of Public Economics 58, 127-141.

Jouvet, P-A, Pestieau, P. and Ponthiere, G. (2010), Longevity and Environmental Quality in An OLG model, Journal of Economics 100(3), 191-216. 
Kan, Haidong, et al. (2008), Season, Sex, Age, and Education as Modifiers of the Effects of Outdoor Air Pollution on Daily Mortality in Shanghai, China: The Public Health and Air Pollution in Asia (PAPA) Study, Environmental Health Perspectives 116(9), 1183.

Kotlikoff, L.J. (1989), Health Expenditure and Precautionary Savings, Chapter 6 in L.J. Kotlikoff (eds.) What Determines Savings?, Cambridge, MIT Press.

Mariani, F., Perez-Barahona, A., Raffin, N. (2010), Life Expectancy and the Environment, Journal of Economic Dynamics and Control 34(4), 798-815.

New York Times (2007) As China Roars, Pollution Reaches Deadly Extremes, August 26.

New York Times (2011) Is China Facing a Health Care Crisis? November 1.

New York Times (2013) On Scale of 0 to 500, Beijing's Air Quality Tops 'Crazy Bad' at 755, January 12.

Ono, Tetsuo (1996), Optimal Tax Schemes and the Environmental Quality, Economics Letters 53, 283-289.

Pautrel, Xavier (2008), Reconsidering the Impact of the Environment on Long-run Growth when Pollution Influences Health and Agents Have a Finite-lifetime, Environmental Resource Economics $40,37-52$.

Pautrel, X. (2012), Pollution, Private Investment in Healthcare, and Environmental Policy. Scandinavian Journal of Economics, 114: 334-357

Palumbo, M.G. (1999), Uncertain Medical Expenses and Precautionary Savings near the End of the Life Cycle, The Review of Economic Studies 66(2), 395-421.

Palivos, T., Varvarigos, D. (2011) Pollution abatement as a source of stabilisation and long-run growth, University of Leicester Working Paper No. 11/04.

Pope, C.A. et al. (1995), Particulate Air Pollution as a Predictor of Mortality in a Prospective Study of U.S. Adults, American Journal of Respiratory and Critical Care Medicine 151, 669674.

Pope, C.A. et al. (2002), Lung Cancer, Cardiopulmonary Mortality and Long-term Exposure to Fine Particulate Air Pollution, Journal of the American Medical Association 287(9), 11321141. 
Samet, Jonathan et al. (2000), Fine Particulate Air Pollution and Mortality in 20 U.S. Cities, The New England Journal of Medicine 343(24), 1742-1749.

Song, Zheng (2011), The Dynamics of Inequality and Social Security in General Equilibrium, Review of Economic Dynamics 14, 613-635.

Soretz, S. (2003), Stochastic pollution and environmental care in an endogenous growth model, Manchester School 71(4), 448-469.

Stokey, Nancy (1998), Are There Limits to Growth? International Economic Review 39 (1), 1-31.

U.S. Environmental Protection Agency, The Benefits and Costs of the Clean Air Act, 1970 to $1990,1997$.

William, R.C. (2002), Environmental Tax Interactions when Pollution Affects Health or Productivity, Journal of Environmental Economics and Management 44, 261-270.

William, R.C. (2003), Health Effects and Optimal Environmental Taxes, Journal of Public Economics $87,323-335$.

World Bank and State Environmental Protection Administration of P. R. China (2007), Cost of Pollution in China — Economic Estimates of Physical Damages.

World Health Organization (2006), Guidelines for Drinking-Water Quality, Third Edition.

Young, Alwyn (2003) Gold into Base Metals: Productivity Growth in the People's Republic of China during the Reform Period, Journal of Political Economy 111(6), 1220-1261. 